\title{
XXI.
}

\section{Zur Lehre von der Aetiologie, der Entstehungs- weise und den Formen der acuten Peritonitis ${ }^{1}$ ).}

Eine experimentelle Untersuchung aus dem Laboratorium des Prof. Fr. Rosenbach in Göttingen.

Von Dr. A. D. Pawlowsky,

Privatdocenten der pathologischen Anatomie und der chirurgischen Pathologie an der medicinischen Akademie in St. Petersburg.

(Hierzu Taf. XIV.)

Die Frage nach der Aetiologie der acuten Peritonitis ist bis jetzt ohne entscheidende Antwort geblieben. Die gegenwärtige Literatur ist mit zufälligen, sich widersprechenden Erklärungen überfüllt. Diätfehler, Erkältungen, rheumatische Insulten, Traumata, Luft u. s. w. werden von verschiedenen Autoren als Ursachen der primären acuten Peritonitis angeführt ${ }^{2}$ ).

Natürlich haben diese Erklärungen nur die Bedeutung „post hoc propter hoc". Nachdem die jetzige Chirurgie sich das Peritonäum als weites Operationsfeld angeeignet hatte, erhob sie auch die Peritonitis unter die Zahl der brennendsten Tagesfragen, welche eine nicht zu umgehende Ausarbeitung und Lösung verlangen. Dennoch scheint es fast, als wolle sie zurücktreten

1) Eine vorläufige Mittheilung der vorliegenden Arbeit wurde deutsch im Centralblatt für Chirurgie 1887 No. 48 veröffentlicht. Ergänzende Versuche in dieser Frage, in dem Laboratorium Prof. Pasteur's in Paris ausgeführt, und meine anderen Arbeiten hielten die Erscheinung dieser Schrift in der jetzigen Gestalt etwas auf. Leider konnte ich die nach der Veröffentlichung meiner vorläufigen Mittheilung erschienenen Arbeiten an dieser Stelle noch nicht berïcksichtigen.

2) Bauer, Acute diffuse Peritonitis. Ziemssen's Handbuch d. spec. Path. Bd. VIII. Hft. II. S. 321. - Bamberger, Handbuch d. spec. Path. u. Ther. Erlangen 1855. S. 680. - Nussbaum, Pitha-Billroth's Chirurgie. III. 2. S.1. 1870. Diction. des sciences méd. Vol. X. 2. p. 484 . 

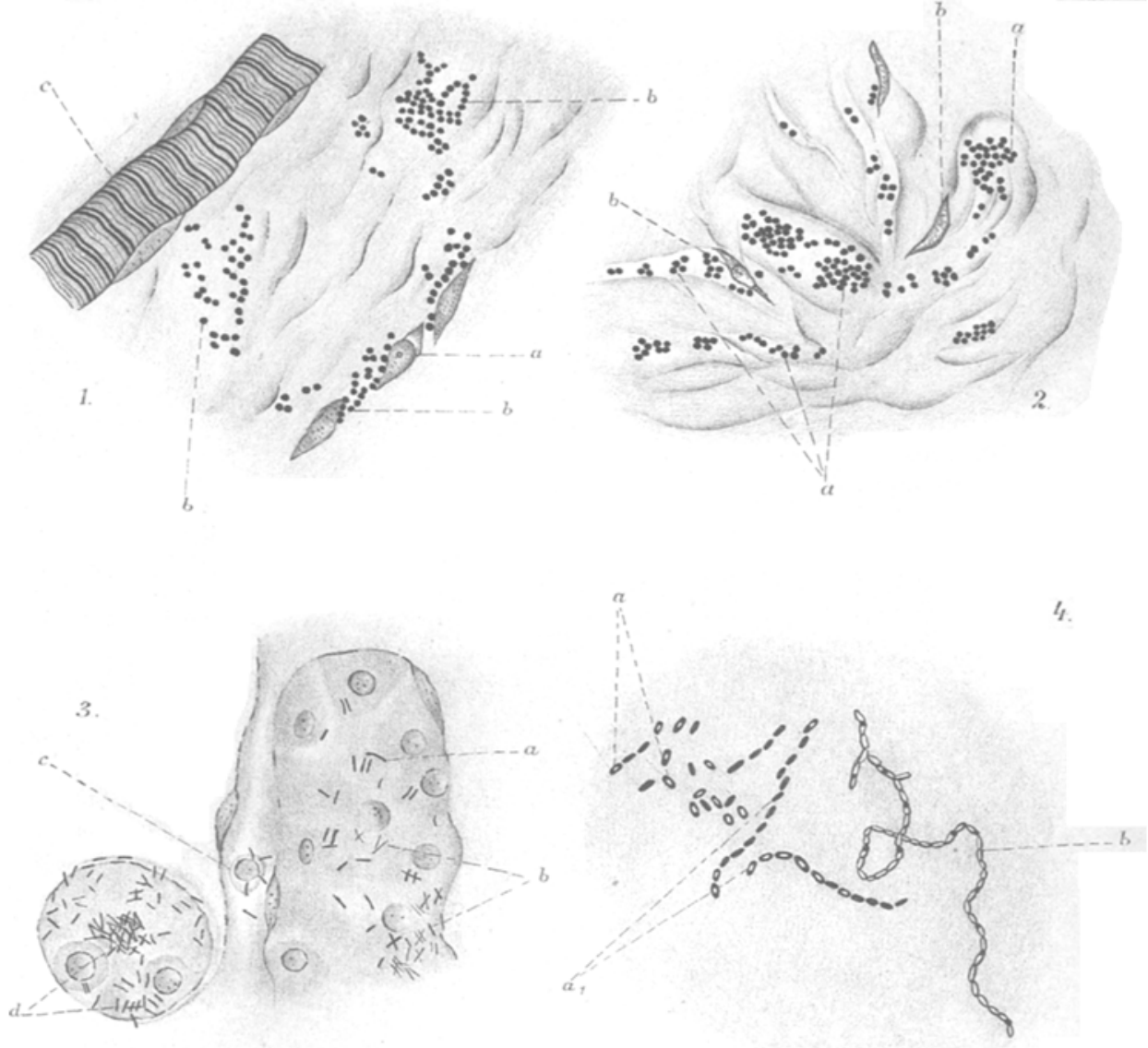

5.

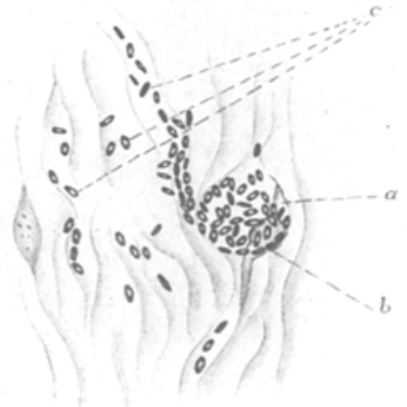

6.

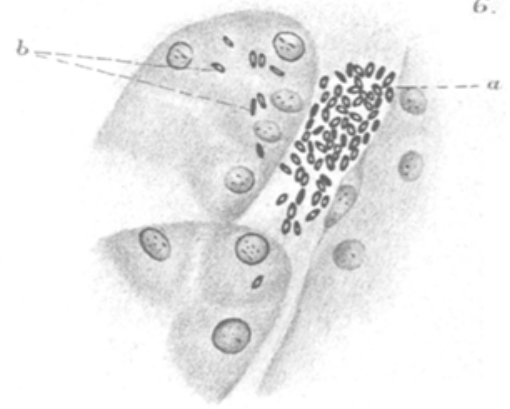


vor der Frage über die Ursachen dieser tödtlichen Krankheit, indem sie sich mit neuen metaphysischen Erklärungen der Art, wie Shock, begnügt, oder sie beschuldigt überall die Mikroben der Luft und zufällige Cmstände bei der Operation. Experimente, welche diese Fragen lösen, und deren auf Thatsachen gegründete Ausarbeitungen fehlen hier fast vollständig, was auch erklärljch ist. Das Peritonäum bedingt durch seine Structur und hohe Empfindlichkeit gegen Reize die Schwierigkeit einer experimentellen Arbeit in dieser Frage. Dieses mag auch die Ursache sein, dass auf diesem Felde nur zwei Bearbeitungen existiren; die eine ist von G. Wegner ${ }^{1}$ ), die andere von Grawitz ${ }^{2}$, von welchen die erstere - vor 10 Jahren entstanden - gegenwärtig veraltet ist und nicht mehr den neuesten Untersuchungsmethoden entspricht, obgleich sie viele werthvolle Thatsachen enthält; die zweite in Anbetracht unerwarteter Resultate weitere Untersuchungen über diesen Gegenstand erfordert. Ausser interessanten physiolugischen Thatsachen, welche ein grosses Verdienst Wegner's bleiben, wie der beständige Abfall der Temperatur des Thieres (auf $13^{\circ}-15^{\circ}$ im Laufe von $5-8$ Stunden) nach weiter Oeffnung des Peritonäum, sowie die Menge und Geschwindigkeit der Aufsaugung von Flüssigkeit im Cavum peritonaei (in der Stunde von $3-8 \mathrm{pCt}$. des Gewichts bei Kaninchen), bewies Wegner, dass das Einpumpen grosser Mengen Luft in das Peritonäum (die Bauwand wurde gespannt wie ein Trommelfell) von den Thieren ohne Schaden ertragen wurde. Die Luft wurde langsam aufgesaugt und bei der nach drei Tagen erfolgten Autopsie fand man keine scharf ausgesprochenen Krankheitserscheinungen im Peritonäum, mit Ausnahme von neugebildetem Bindegewebe auf der Kapsel einiger Organe (S. 42) und Erweiterung der Lymphgefässe. Ferner führte $W$ egner eine lange Reihe von Experimenten mit verschiedenen Flüssigkeiten aus, in der Absicht, den Grund der acuten Peritonitis klar darzulegen. Nach der Einspritzung von leicht resorbirbaren Flüssigkeiten in den

1) G. Wegner, Chirurgische Beobacbtungen über die Peritonäalböhle mit besonderer Berkicksichtigung der Ovariotomie. Verhandlungen der deutschen Gesellschaft für Chirurgie (V. Congress). Berlin 1877. S. 1-97.

2) Grawitz, Statistischer und experimentell-pathologischer Beitrag zur Kenntniss der Peritonitis. Charité-Annalen Jahrg. XI. 1886. S. 776. 
Bauchraum von Kaninchen $\left(20-40 \mathrm{~cm} 35^{\circ}\right.$ warmen Wassers, 1 pCt. Chlornatriumlösung, frischen Menschenharnes, frischen defibrinirten Blutes, künstlich hergestellter Molken, Jodkali) beobachtete er keine sichtbaren pathologischen Erscheinungen bei den Thieren. Die Flüssigkeiten wurden von dem Peritonäum aufgesaugt. Nach Tödtung der gesund gebliebenen Thiere fanden sich keine pathologischen Veränderungen im Peritonäum (S. 36). Oelige Flüssigkeiten und Emulsionen (Olivenöl und Milch) wurden ebenfalls resorbirt, wenn auch langsamer und nach vorhergehendem Austritte eines flüssigen Exsudates in das Periotonäum, sowie theilweiser Emulgirung des eingespritzten Oels. Beim Einbringen concentirter Lösungen von Zucker oder Glycerin in das Peritonäum beobachtete Wegner im Anfange eine Verdünnung dieser Lösungen durch das Exsudiren einer grossen Menge von Flüssigkeit in das Peritonäum und darauf ihre Aufsaugung. Beim Einbringen von Stoffen in Pulverform (schwarzer chinesischer Tusche, Kohlenpulver u. s. w.) blieben die Thiere munter und gesund, in dem Peritonäum aber lagerte sich Pigment ab. Fein gepulverte Stoffe, welche den Durchmesser der weissen Blutkörperchen nicht überschreiten und sich in der Lymphbahn fortbewegen können, werden überhaupt aus dem Peritonäalsacke aufgesaugt. Körper von grösserer Dimension kapseln sich im Peritonäum ein. Versuche mit Flüssigkeiten, welche Mikroorganismen enthielten, in kleinen Quantitäten, 6, 12, $25 \mathrm{~cm}$, gaben widersprechende Resultate. Ein Filtrat aus faulendem Muskelinfus von $12 \mathrm{ccm}$ verursachte nach 8 Stunden den Tod (S. 42). Ein wässeriges Filtrat aus dem Inhalte des Dickdarmes blieb ohne bestimmtes Resultat; übrigens wurden im Peritonäum eines Kaninchens nach 12 Stunden gelbe eingekapselte Massen und Verwachsungen, sowie gelbliche Heerde im Herzen und in den Nieren gefunden. Ein Filtrat von fauliger Flüssigkeit (welcher?) verursachte bei einem Kaninchen, welches nach 24 Stunden getödtet wurde, "leichte fleckig punktirte Röthung", d. b. kleine Hämorrhagien mit einer Masse von Mikroorganismen in den Lymphgefässen des Diaphragma; das zweite Kaninchen starb nach zwei Stunden (eine Menge Mikroorganismen im Blute) -- das dritte nach 19 Stunden (Exsudat im Peritonäum), - beim vierten Thiere, einem Hunde, welcher nach 14 Tagen getödtet wurde, fanden 
sich gelbliche Heerde mit Mikroben im Herzen und in den Nieren, - beim fünften wurde nach 10 Tagen auf dem Peritonäum eine zarte gelbliche Auflagerung gefunden (S. 52). Nach Einspritzung von Eiter (welchem?) erhielt Wegner Peritonitis bei Hunden und Kaninchen. Versuche mit Einspritzung fauler Flüssigkeiten in grossen Quantitäten $(50-60 \mathrm{~cm}$ ) hatten den Tod zur Folge.

Auf Grund aller seiner Versuche zog Wegner folgende Schlüsse:

1. Das Peritonäum ist eine innere Höhle von grosser Oberfläche, ungefähr gleich der Oberfläche des ganzen Körpers. (Nach Wegner's Berechnung beträgt die Oberfläche des Peritonäums $17,182 \mathrm{qcm}$, bei $17,502 \mathrm{qcm}$ des Körpers).

2. Es besitht eine enorme Resorptionsfähigkeit. Es ist dies der grösste Resorptionsapparat des Körpers (S. 53), welcher im Stande ist, Narcotica rascher aufzusaugen, als das Unterhautzellgewebe, in einer Stunde 3-8 pCt. des ganzen Körpergewichtes.

3. Dieser Apparat besitzt eine ebensolche Transsudationsfähigkeit.

4. Es besitat eine bedeutende Plasticität seines Gewebes.

Geringe Mengen resorbirbarer Flüssigkeiten verschwinden rasch aus dem Peritonäum. Faulende Flüssigkeiten in geringer Menge $(15 \mathrm{ccm})$ werden nach der Meinung Wegner's ebenfalls schadenlos aufgesaugt; um Peritonitis zu erzeugen, müssen diese Flüssigkeiten im Peritonäum zurückgehalten werden und sich zersetzen, d. h. sie müssen in so bedeutender Quantität eingespritzt werden, dass dieselbe das stündliche Resorptions-Aequivalent des betreffenden Thieres übertrifft.

Mit einem Worte, unter normalen Bedingungen bietet das Peritonäum so günstige Verbältnisse zur Wundheilung dar, wie kein anderes Organ des menschlichen Körpers (S. 71). Bei Eiterung des Peritonäum können in kürzester Zeit bedeutende Mengen aus ihm resorbirter schädlicher Stoffe in den Blutkreislauf gelangen (S. 72), so dass die wahre Ursache des Todes in acuten Fällen nicht die Peritonitis ist, sondern die Blutvergiftung durch Aufsaugung von Stoffen aus dem Peritonäum.

In Todesfällen ohne jede pathologische Veränderung im Peritonäum, welche durch Shock erklärt werden, ist die wahre Ursache eine acute Sepsis (S. 87). Zürückhaltung derFlüssigkeit 
und ihre verlangsainte Aufsaugung sind die nöthigen Bedingungen zum Auftreten der Peritonitis. -

Ein sonderbares Schicksal hatte in der Folge diese bemerkenswerthe Arbeit: sie bereicherte die Physiologie mit Schlüssen und Thatsachen von bedeutsamer Wichtigkeit, blieb aber-dessenungeachtet unbemerkt und wurde von den Physiologen vergessen. Die gewagten Schlüsse Wegner's wurden inzwischen in die $\mathrm{Pa}$ thologie vollständig aufgenommen und werden bis in die Neuzeit wiederholt. Er selbst schrieb, dass das Peritonäum so günstigen Bedingungen zur Heilung der Wunden darbiete, wie kein anderes Organ. Bei alledem starben und sterben - besonders wegen Darmleiden - Laparatomirte viel öfter, als nach anderen chirurgischen Operationen. Dadurch entstand zwischen Theorie und Praxis ein offener Widerspruch, und nach und nach kam es zu einer stillschweigenden Uebereinkunft. Wenn auch die Praxis Wegner's ermuthigende Schlüsse wiederholt und mit ihm nicht streitet, umgiebt sie sich dennoch mit einer Menge von Vorsichtsmaassregeln bei der Laparatomie. Mit der Zeit erhielten diese Wegner'schen Schlüsse einen mehr und mehr entschiedenen Charakter, welchen er selbst ihnen durchaus nicht zuschreiben wollte und konnte, da seine Schlüsse seinen Experimenten und Beobachtungen gar nicht entsprachen.

Wenn er ohne Schaden Wasser von $40-35^{\circ}$ in das Peritonäum einspritzte, so hatte er sehr wahrscheinlich das Wasser im Laboratorium bis zu einem höheren Grade erwärmt und dann bis $40^{\circ}$ erkalten lassen; aber unter solchen Bedingungen konnten alle Mikroben abgestorben sein. Ferner spritzte er ohne Schaden frischen Urin ein; aber Urin eines gesunden Menschen enthält keine Mikroben. Er führte frisches Blutserum ein, welches auch keine Mikroben besitzt. Und wenn auch bei einem oder dem anderen seiner Versuche mit verschiedenen Flüssigkeiten Sporen von Mikroben in geringer Menge in das Peritonäum gerathen konnten (wie bei den Versuchen mit frischer Milch und Oel), so waren diese Mikroben nicht pathogen. Wenn dieselben für die verschiedenen Gewebe des Körpers unschädlich waren, so waren sie es natürlich auch für das Peritonäum, denn dieses Gewebe ist denselben Gesetzen des Wachsthums und der Zerstörung unterworfen, wie die übrigen Gewebe des Körpers. 
Da Wegner mit der grossen Armee pathogener Mikroben unserer Tage unbekannt war, so zog er den falschen Schluss, dass verschiedenartige Flüssigkeiten rasch und ohne Schaden von dem Peritonäum aufgesaugt würden. Wenn er diesen Flüssigkeiten auch nur einen Tropfen pathogener Mikroben hinzugefügt hätte, so würde er möglicher Weise zu einem ganz entgegengesetzten Resultate gekommen sein.

Sein weiterer Schluss, dass faulende Flüssigkeiten in geringer Quantität bis zu $15 \mathrm{ccm}$ ebenfalls ohne Schaden von dem Peritonäum aufgesaugt werden, steht durchaus nicht im Einklange mit seinen eigenen Versuchen. So beobachtete er nach einer Einspritzung von 6-12-25 ccm (siehe oben) eines wässerigen Filtrates aus faulendem Muskel bald den Tod nach: 8 Stunden, bald gelbe eingekapselte Massen (Eiter?), bald Verwachsungen im Peritonäum und endlich gelbliche Höhlen im Herzen und in den Nieren (Metastasen?). Von 5 Thieren einer anderen Reihe wurde bei einem Kaninchen nach 24 Stunden eine leichte gefleckte Röthung gefunden (Peritonitis haemorrhagica acutissima?); ein anderes Thier verendete pach 2 Stunden, ein drittes nach 19 Stunden und bei dem vierten Thiere, einem Hunde, wurden gelbliche Höhlungen im Herzen und in den Nieren, bei dem fünften eiterige Peritonitis gefunden (S. 52). Nach Einspritzung von Eiter entstand eiterige Peritonitis bei Hund and Kaninchen.

Faulende Flüssigkeiten wurden also selbst in geringer Menge bei Wegner's Versuchen gar nicht aufgesaugt, sordern tödteten die Thiere. Ausserdem können diese Versuche in vieler Hinsicht keine Bedeutung haben. Denn erstens brauchten in den faulenden Stoffen Wegner's keine pathogenen Mikroben zu sein; ferner ist die Virulenz der Faulfüssigkeit an verschiedenen Tagen zu verschiedenen Perioden äusserst verschieden') und es kommen Perioden vor, in welchen sie ohne allen Einfluss auf Thiere bleibt. Endlich können Experimente mit faulenden Stoffen, in welchen sich in grosser Menge eine unbekannte Mischung verschiedener Mikroben befindet, nicht als Beweise dienen. Obgleich Wegner bei einigen seiner Versuche nicht mittheilt, was für faulende Stoffe und was für einen Eiter er benutzte, so hatten seine Experimente

1) v. Paschutin, Cursus der allgemeinen und experimentellen Pathologie. Bd. I. Th. I (russiscb). 
mit grossen Quantitäten $(50 \mathrm{ccm})$ jedenfalls den Tod der Thiere zur Folge.

Die Irrschlüsse Wegner's, indem sie in die Pathologie aufgenommen wurden, erhielten in der gegenwärtigen Literatur etwa folgende Formulirung: "das Peritonäum ist ein ausserordentlich widerstandsfähiges Gewebe, in welchem die verschiedensten eingespritzten Stoffe rasch und ohne Schaden für den Organismus aufgesaugt werden." -

Die Arbeit Wegner's wurde von den Physiologen nicht wiederholt, sie blieb lange Zeit uncontrolirt von den Pathologen und nur Grawitz richtete unlängst seine Aufmerksamkeit auf die acute Peritonitis. Dieser Experimentator betrachtete die Angaben Wegner's "ohne Weiteres als feststehend"1) und unterwarf nur den pathologischen Theil derselben einer experimentellen Untersuchung; aber auch hier nahm er eine ganze Reihe von Angaben Wegner's auf guten Glauben hin an und ging auf dessen Schlüsse ein, welche aus den beobachteten Thatsachen selbst nicht folgten ${ }^{2}$ ). Die Hauptresultate seiner eigenen Untersuchung formulirt Grawitz im Anfange derselben, vor der Mittheilung seiner Versuche, ungefähr in folgenden Worten:

Eine grosse Zahl der Bakterienarten, welche ich in die Bauchhöhle der Kaninchen injicirte, in Reinculturen oder gemischt, konnte in keinem Falle (unter keiner Bedingung) eine eiterige Peritonitis hervorrufen. Dazu ist eine geringe Anzahl bestimmter Arten befähigt; aber sogar pyogene Kokken oder Bacillen bringen diese Wirkung nur unter gewissen Bedingungen hervor, so dass das Eindringen von pyogenen Spaltpilzen in die Bauchhöhle nur eine nothwendige vorbereitende Bedingung, aber nicht die einzige Ursache der allgemeinen Peritonitis ist.

1) Grawitz, ebend. S. 777 .

2) In dem Referate über Wegner's Arbeit schreibt Grawjtz: „Flüssigkeiten, wolche geformte Theilchen enthalten (Tusche, .... Milch, Blut, Eiter), werden resorbirt,.... keïne Ausuahme machen Flüssigkeiten, welche Mikrokokken und Bakterien enthalten," - ein Schluss, welcber, wje oben ausgesprocben, aus den eigenen Schlüssen Wegner's genommen, nicht im Einklange steht weder mit seinen Beobachtungen, noch mit seinen Versuchen. Denn nach Einspritzung von Eiter starben Wegner einige Thiere an Peritonitis; nach Einspritzung von faulender Flüssigkeit mit Bakterien kam ebenfalls eine Reihe von Thieren um. 
Diesen allgemeinen Standpunkt erhärtete Grawitz durch eine Reihe von Versuchen:

I. Bei Einbringen von Bakterien, welche keine Eiterung erzeugen, in die normale Bauchhöhle beobachtete er gar keine schädlichen Folgen, wenn er auch Bakterien in grosser Quantität einbrachte, sei es flüssig, sei es gemischt mit geformten Theilchen. Die Prior-Finkler'schen Bacillen, Bacillus cholerae asiaticae, Bacillus subtilis, kurze Stäbcheu und zwei Arten von Kokken, aus dem Darminhalte des Kaninchens isolirt, zeigten sich bei der Injection in das Peritonäum unschädlich. Ein Aufguss von Excrementen mit festen Theilen des Darminhaltes in das Peritonäum eingespritzt, wurde ohne Schaden resorbirt, während die festen Bestandtheile sich einkapselten. Nach der Meinung von Grawitz bewirkt also der Darmsaft keine Peritonitis. Er enthält auch keine dem Peritonäum schädlichen chemischen Stoffe, denn grosse Mengen gekochter fäcaler Massen sind für das Peritonäum ebenfalls unschädlich.

II. Die Einführung von Mikroben, welche in grosser Menge keine Eiterung in der normalen Bauchhöhle hervorrufen, bewirken bei gestörter Resorptionsthätigkeit entweder allgemeine Sepsis, oder werden ohne Folgen aufgesaugt.

III. Die Einspritzung von Mikroben, welche Eiterung bewirken, sind für die normale Bauchhöhle ebenso unschädlich, wie die Einspritzung indifferenter Mikroben. Grawitz spritzte eine trübe Emulsion aus Staphylococcus albus, dann aureus und Streptucoccus pyogenes albus in $10 \mathrm{ccm}$ Wasser in das Peritonäum ohne Schaden für die Thiere. 10 procentige Lösung von $\mathrm{NaCl}$ mit Decoct. Salep und Staph. aureus rief auch keine Peritonitis hervor.

IV. Das Einbringen von eiterregenden Kokken in die normale Bauchhöhle bringt eiterige Peritonitis hervor: a) wenn das Peritonäum schwer resorbirbare Nährflüssigkeit enthält; b) wenn ätzende Stoffe eingebracht werden, welche das Gewebe des Peritonüums zerstören und den Boden für die Ansiedelung in das Gewebe vorbereiten; sie rufen ein allgemeines Exsudat hervor. c) Ausserdem entsteht eiterige Peritonitis sicher, wenn eine Wunde der Bauchwand die Ansiedelung der Infectionsträger begünstigt. A us einer kleinen Phlegmone des Peritonäum entwickelt 
sich gewöhnlich allgemeine Peritonitis. Sogar der Einstichkanal genügt zum Eindringen einer Masse von Mikroben, welche sich aus diesem ersten Heerde dem Gewebe des Peritonäum entlang vermehren. Das Bauchfell sondert dann ein eiteriges Exsudat mit Mikroben in das Cavum peritonaei ab in solcher Menge, dass dieselbe die Resorptionsfähigkeit des Peritonäum überwiegt.

"Der Unterschied zwischen meinen Ergebnissen und der Meinung Wegner's" schreibt Grawitz zum Schlusse, "besteht darin, dass Wegner das Peritonäum als eine Höhle betrachtet (die Serosa als Höhle nach Wegner), während nach meinen Untersuchungen die Wände dieser Höhle eine grössere Bedeutung haben" (die Serosa als Gewebe nach Grawitz).

Wenn wir die Arbeit von Grawitz genauer betrachten und seine Resultate mit denjenigen der vorhergehenden Wegner'schen Arbeit zusammenstellen, so finden wir, dass Grawitz mit sich selbst nicht ganz einig ist und in seinen Resultaten den Schlüssen Wegner's widerspricht. Indem er auf Grund seiner Versuche die Resultate seiner Arbeit resumirt, schreibt er, dass eine Peritonitis durch Injection in die Bauchhöhle nur eine beschränkte Anzahl von Arten hervorrufen könne, am Ende aber wiederruft er seine Meinung über das Peritonäum als Höhle (6) und sagt, dass zur Entstehung einer Peritonitis ein Einstichskanal, eine Wunde der Bauchwand und die Verbreitung der Mikroben aus dieser Wunde über die Peritonäalwand nothwendig seien. Ausser dem Widerspruche sind für seine letzte Vorstellung über das Peritonäum als Gewebe (Häutchen) bei Grawitz gar keine factischen Belege angeführt, im Gegentheile, alle seine Versuche sind mit Einspritzungen der verschiedensten Stoffe in die "Peritonäalhöhle " ausgeführt worden. Indem er mit Wegner dessen gewagten Schluss wiederholt, dass weder Luft, noch medicamentöse Stoffe, noch Blutserum, noch Galle, Urin, concentrirte Lösungen, Tusche, Kohle, rother Präcipitat, weder faulende Stoffe mit Mikroben noch Eiter Peritonitis erregen, unterliess es Grawitz, unter dem Einflusse der Ideen und Argumente Weguer's die Schlüsse des letzteren mit seinen Thatsachen zu vergleichen, unterwarf sie nicht von Neuem einem Controlexperimente und behandelte sein eigenes Impfmaterial nicht streng kritisch. Vor allen Dingen entstand aus allem diesem 
eine Controverse zwischen Wegner und Grawitz. Grawitz behauptet, dass fauler Stoff bei Wegner keine Peritonitis hervorruft; aber inzwischen starben die Thiere Wegner's nach Einspritzung von faulem Stoffe durch Peritonitis, wie wir oben gezeigt haben. Durch Einspritzung von Eiter entstand in seinen Versuchen bei einem Hunde und Kaninchen Peritonitis purulenta; im Gegensatze hierzu beobachtete Grawitz nach Einspritzung von $10 \mathrm{ccm}$ trüber wässeriger Emulsion pyogener Mikroben gar keinen pathologischen Effect bei seinen Thieren. Versuche mit pyogenen Mikroben bilden die Hauptsache und den Mittelpunkt der Arbeit von Grawitz. Nun aber ist die Unsehädlichkeit seiner Mikroben für das Peritonäum äusserst sonderbar und unerwartet. Wir kennen unter den pyogenen Mikroben den Staphylococcus aureus, - ein äusserst bösartiges Mikrob, welches überall, wo es hingerathen mag, Eiterung mit Nekrose hervorruft. Die Versuche Garré's an sich selbst bewiesen, dass es, selbst in die Haut eingerieben, eine stürmische und schwere Eiterung verursachte. Dagegen ist das Mikrob nach Grawitz für das Peritonäum unschädlich. Möglicher Weise waren die benutzten Kokken unwirksam, die Culturén nicht virulent?

Wie das nun sein mag, es ist klar, dass für die Frage nach der Aetiologie der Peritonitis, durch die Resultate von Grawitz fast noch mehr Räthsel geschaffen wurden, als sie vor seiner Arbeit besass. In der letzten Zeit beschäftigte sich Mikulicz mit dieser Frage und brachte einige werthvolle Thatsachen ${ }^{1}$ ) zu Tage. Die Resultate seiner Versuche trug er auf dem XVI. Chirurg.-Congress in Berlin vor. Da er sich für die perforative und septische Peritonitis interessirte, so rief er die letztere bei Hunden hervor, indem er ihnen eine Darmschlinge eröffnete und den Inhalt in das Cavum peritonaei fliessen liess. Die Thiere starben nach 24 Stunden. Er versuchte solche Formen von Peritonitis zu behandeln und fand, dass Acid. carbol. und Sublimat zur Behandlung solcher Peritonitiden nicht taugen, da sie selbst auf das gesunde Peritonäum schädlich wirken. Im Gegentheile wirken Acid. borac. und Acid. salicyl. bedeatend besser. Von 18 Hunden, bei welchen Perito-

1) Mikulicz, Centralbl. f. Chirurgie. Beilage 2. No. 25. 1887. 
nitis nach dem Einschnitte des Darmes entstanden war und welche mit Salicylsäure behandelt wurden, gelang es, 50 pCt. zu retten. Die letzten Ergebnisse von Mikulicz sind äusserst interessant. Leider hat er nicht angegeben, weshalb seine Hunde nach Darmschnitt nach 24 Stunden an Peritonitis umkamen? Es ist klar, dass Gift in dem herausfliessenden Darmsafte vorhanden war; sicher gehen auch Menschen durch den Darminhalt bei Peritonitis perforativa zu Grunde; was ist nun das für ein Gift im Darminhalte? Sind es Mikroben des Saftes oder Ptomaine oder Toxine? Das blieb durch Mikulicz unerklärt. Ebenso hat er sich darüber nicht ausgesprochen, weshalb das Sublimat und die Carbolsäure dem Peritonäum schädlich sind. Riefen sie eine hämorrhagische oder eiterige Peritonitis hervor - mit oder ohne Mikroben aus den Gedärmen u. s. f.? Mit einem Worte, es giebt auf diesem Felde viele Fragen, welche noch unberührt sind und der Lösung harren. Die Aetiologie der acuten Peritonitis muss einer neuen, rein experimentellen Bearbeitung unterworfen werden. Deshalb ging ich auch gern auf den Vorschlag des Herrn Prof. Rosenbach ein, mich in diesem schweren und wichtigen Gebiete einer experimentellen Arbeit in seinem privaten Laboratorium zu unterziehen.

Was die Methode der Arbeit anbelangt, so wurden zwei Bestrebungen verfolgt: Asepsis des Versuches und Vermeidung, die Eingeweide zu verwunden bei der Injection von Flüssigkeiten in das Peritonäum. Es wurden deshalb bei den Thieren die Haare auf dem Bauche vor dem Experimente abgeschoren, darauf wurde mit Carbolsäure gewaschen, dann mit Sublimatlösung 1:1000, dann zum zweiten Male eingeseift, abrasirt, die Haut darauf noch einmal mit Sublimatlösung abgewaschen und sogleich mit einer Lage Sublimatwatte bedeckt. Die Hände wurden ebenfalls mit obiger Sublimatlösung desinficirt. Die Instrumente wurden in einem Gasofen sterilisirt, Spritzen und Apparate zur Einspritzung im strömenden Dampfe. Nachdem mit einem sterilisirten Skalpell die Haut und ebenso das Unterhautzellgewebe in einer Länge von $\frac{1}{2}-1 \mathrm{~cm}$ durchschnitten war, wurden die Muskeln mit einem scharfen Haken in die Höhe gehoben. Dann wurde auf der Spitze der Erhöhung ein durch den Gasofen sterilisirter Trokar mit stumpfem Stilet - zur 
Vermeidung einer Verletzung der Eingeweide - eingesetzt. Das Stilet wurde herausgenommen und durch den Trokar mit einer sterilisirten Spritze die bestimmte Injectionsmasse eingespritzt (bakterienhaltige oder solche chemische Flüssigkeiten, welche die Sterilisirung mit dem strömenden Dampfe nicht übertragen können, oder auf kaltem Wege sterilisirte). Die durch den strömenden Dampf sterilisirten chemischen Substanzen wurden in einen besonderen Apparat geschüttet, bestehend aus einer graduirten, nach unten ausgezogenen, gläsernen Röhre, oben mit einem Pfropfen geschlossen, durch welchen eine gebogene gläserne Röhre geht. Auf den unteren, nach unten gezogenen, gläsernen Theil wird eine Guttapercharöhre mit einer Canüle am freien Ende und einer Klammer in der Mitte gesetzt; auf der oberen gläsernen Röhre befindet sich ebenfalls eine Guttapercharöhre mit Watte. Dieser, mit der zu injicirenden Flüssigkeit gefüllte Apparat wurde im strömenden Dampfe sterilisirt, von sterilisirter Gaze umgeben und - nach Ábkühlung - die Flüssigkeit ohne Oeffnung des Apparates durch die obere Röhre in das Peritonäum geblasen.

Dieser Apparat sichert eine vollständige Asepsis des Versuches. Leider verstopft sich manchmal die Canüle beim Eindringen durch die Bauchmuskeln mit Stückchen derselben, welche zuweilen beim Herausblasen einen grossen Widerstand leisten. Die Manipulation aber mit Spritze und Stilettrokar ist bedeutend bequemer und bei Uebung und Aufmerksamkeit im Sterilisiren aller Instrumente giebt sie eben so vorwurfsfreie Resultate.

Nach der Einspritzung und Desinfection wurde die Wunde rasch mit Jodoformcollodium und hydrophiler Watte geschlossen. Die beschriebene Methode entsprach vollständig allen strengen Anforderungen, welche an die Asepsis sowohl, wie an das Experiment gestellt werden können.

Ein Mal wurde eine Eiterung im Stichkanal und einmal Verletzung der Eingeweide im Peritonäum beobachtet. Alle übrigen Versuche waren, wie die Untersuchung post mortem ergab, frei von solchen Fehlern. Nach Einspritzung chemischer Flüssigkeiten konnten durch post mortem Untersuchungen keine Mikroben im Peritonäum entdeckt werden. Nach Einspritzungen von Culturen wurden nur diese Reinculturen gefunden, auch nach 
Aussaat post mortem. Mit dieser Methode wurden 13 Reihen (Serien) oder 110 Versuche ausgeführt. Je nach dem Charakter und dem leitenden Gedanken zerfallen diese Versuche streng in 4 Hauptgruppen: Versuche mit Einwirkung 1) verschiedener chemischer Substanzen auf das Peritonäum, 2) von Mikroben, 3) des Darmsaftes, 4) gemischter Einwirkung, einer Combination oder einer Mischung von chemischen Stoffen mit Mikroben auf das Peritonäum.

Die Klasse der Reizerreger des Peritonäum ist ungewöhnlich gross. Es ist freilich unmöglich, mit allen den verschiedenartigen Repräsentanten der chemischen Gruppen zu experimentiren. Deshalb begnügten wir uns auch mit einem der stärksten Reizerreger des thierischen Gewebes und gingen dann zu den Versuchen mit speciell für das Peritonäum wichtigen chemischen Reizerregern über, welche in dem Laboratorium der Bauchhöhle bereitet werden, und endlich beschäftigten wir uns mit den chemischen Lebensproducten der Bakterien; anders ausgedrückt, unsere Versuche über die Einwirkung der chemischen Substanzen auf das Peritonäum zerfallen in 3 Gruppen: Versuche 1) mit Oleum crotonis; 2) mit Verdauungsfermenttrypsin und 3) mit den chemischen Lebensproducten des Staphyl. aureus und Streptococcus erysipelatis. Oleum crotonis wurde gewählt, theils weil es einer der stärksten Reizerreger ist, theils weil es eine Substanz ist, welche nach der Meinung verschiedener Autoren selbständig eine Eiterung zu erregen vermag. Das Auftreten der eiterigen Peritonitis - ohne Mikroben, - nur unter dem Einflusse des 0l. crot. würde einen ausserordentlich werthvollen Beitrag zur Aetiologie der Peritonitis und zur Erklärung der Ursache der Eiterung darstellen. Man könnte auch denken, dass unter der Einwirkung eines starken Reizes der Serosa und der Darmwände die letzteren möglicherweise Mikroben aus dem Lumen der Gedärme in das Cavum peritonaei durchlassen, und damit an der Erzeugung einer secundären infectiösen Peritonitis theilnehmen.

Das Crotonöl wurde in Emulsion mit Gummi arabicum eingespritzt. Die Emulsion wurde in den oben beschriebenen Apparat gebracht und im strömenden Dampfe sterilisirt. Die Quantität des injicirten 01 . croton. schwankte zwischen 6 und 
$\frac{1}{10}$ Tropfen. Die letztere Quantität ertrugen die Thiere ohne Schaden. Bei den grösseren Dosen wurde Peritonitis haemorrhagica mit blutigem Exsudate, dessen Intensität von der Menge des eingespritzten Crotonöles abhing, beobachtet. Unter dem Mikroskope bestand das Exsudat fast ausschliesslich aus rothen Blutkörperchen unter seltener Beimischung von weissen. Auf Deckglaspräparaten, in Aussaat auf Agar-Agar und in Plattenculturen wurden niemals Mikroorganismen angetroffen.

Im Folgenden werde ich nur einige typische Versuche mit ihren Einzelheiten anführen. Die übrigen werden der Kürze halber in der beigefügten Tabelle aufgezeichnet werden.

Versuch 5 mit Crotonöl. 28. Juni 1887. Einem grossen schwarzen Kaninchen wurden durch den sterilisirten Apparat 2 Tropfen 01. crot. in Emulsion von Aq. dest. 49,0 mit Gummi arabicum 1,0 eingespritzt. Das Kaninchen liegt unruhig auf dem Banche nach dem Versuche. Am anderen Tage unrubig, wirft sich umber von Zeit zu Zeit, kann nicht geben, gegen 11 Ubr liegt es auf der Seite, den Kopf rückwärts gebogen, ist sterbend. Wird durch Stich in die Medulla oblongata getödtet. Section: Grosse Ansammlung hämorrhagischen Exsudates, starke Hyperämie und viele Extravasate und Ecchymosen im Peritonäum. Diagnosis: Peritonitis baemorrhagica gravis. Mikroskopisch uritersucht besteht das Exsudat ausschliesslich aus rothen Blutkörperchen ohne Mikroben. Nach Aussaat aus dem Exsudate auf Platten und in Reagenzgläschen mit Gelatine wachsen gar keine Mikroben.

Versuch 13. 15. August. Einer grossen schwarzen Hündin wurden aus oben erwähntem gläsernen Apparate 2 Tropfen 01 croton. in $25 \mathrm{~cm}$ Wasseremulsion mit Gummi arabic., welche im strömenden Dampfe wäbrend drei Tagen täglich 15 Minuten Jang sterilisirt war, eingespritzt. Die Haare auf dem Bauche des Hundes wurden vorher rasirt und gewaschen. Der Hund war ausserdem in einer Wanne und darauf das Operationsfeld mit Sublimat abgewaschen worden. Zuletzt wurde das Thier in ein reines Laken eingehüllt. Die Instrumente wurden im strömenden Dampfe sterilisirt und darauf in 5 procentiger Carbolsäurelösung. Die kleine $W$ unde von $1 \mathrm{~cm}$ ging bis zur Muskellage und wurde mit Jodoformcollodium bedeckt. Listerverband aus 8 Lagen Sublimatgaze und Binde ${ }^{1}$ ). Das Thier starb in der Nacht. Section: Die Wunde und der Verband trocken, obne alle Anschwellung. Intensive hämorrhagische Peritonitis. Injection des Peritonäum und Mesen-

1) Das Experiment konnte mit einer vollkommenen Asepsis ausgeführt werden, dank der ausserordentlichen Zuvorkommenheit des Herrn Prof. Rosenbach, welcher mir für diesen Zweck den Zutritt in den poliklinischen Operationssaal der Klinik des Herrn Professor König gestattete. 
terium. Viele Extravasate. Geringe Menge blutig-serösen Exsudates. Mikroben wurden weder mikroskopisch, noch in Plattencultur gefunden.

Versuch 32 und 33. 26. August. Zweien Kaninchen wurde je $\frac{1}{10}$ Tropfen 01. croton. in Wasseremulsion mit Gummi arabicurn eingespritzt. Beide ertrugen die Injection gut und blieben am Leben.

In Anbetracht der Möglichkeit, dass bej Perforativeritonitis die Fermente des Darmsaftes eine Rolle spielen könnten, wurden in der $z$ wejten Reibe der Experimente Injectionen mit Verdauungsermenten ausgeführt.

Vor den zu unternehmenden Versuchen war es nöthig festzustellen, ob diese Fermente keine Mikroben enthielten: verändern sie sich nicht durch Sterilisiren in hoher Temperatur, und welchen Einfluss haben sie auf das Wachsthum und die Entwickelung der Mikroorganismen? Deshalb wurden wässerige Lösungen von Trypsin und Pancreatin (Schuchardt in Görlitz) auf Fleisch-Pepton-Gelatine gesät. Dabei entwickelten sich aus der Pancreatinlösung Mikroorganismen. Die Saat aus Trypsin aber blieb steril. Für die weiteren Versuche behielten wir deshalb das Trypsin bei. Um festzustellen, welchen Einfluss das Sterilisiren bei hoher Temperatur auf dasselbe baben könnte, wurden zwei Reihen von Parallelversuchen angestellt. In der einen Reibe wurden in Reagenzgläschen grosse Stücke geronnenen Eiweisses mit gekochter und ungekochter wässeriger Trypsinlösung gebracht; in der zweiten Reibe wurde dasselbe nur mit kleinen Stücken Eiweisses ausgeführt. Alle Reagenzgläschen wurden in den Thermostaten bei $30^{\circ}$ gestellt. Nach 16 Stunden zeigte sich, dass gekochtes Trypsin das Eiweiss weder verdaut noch aufgelöst hatte, aber das ungekochte hatte obne Rest die kleinen Stückchen verdaut und aufgelöst, ebenso das Meiste der grösseren Stücke.

Zur Beleuchtung der Frage, welchen Einfluss das Trypsin auf das Wachsthum und die Entwickelung der pathogenen Mikroben haben könnte, wurde 0,1 $\mathrm{g}$ Trypsin in $15 \mathrm{ccm}$ sterilisirten Wassers aufgelöst und in 6 sterilisirte Reagenzgläschen vertheilt. In drei von ihnen wurden Staphylococcus aureus und Bacillus pyocyaneus gesät; diese drei wurden in den Thermostaten gestellt. Nach 2-4-6 Stunden wurde die Saat dieser Species von Mikroben auf reines Fleischpepton-Agar-Agar übertragen. Nachdem aus den drei übrigen Reagenzgläschen das Trypsin zu flüssigem. (nahe dem Erkalten) Agar-Agar zugegossen und mit dem letzteren vermischt war, wurden oben erwähnte Mikroben vor dem vollständigen Erkalten gesät.

Es zeigte sich, dass die oben erwähnten Mikroben bei allen Verpflanzungen mit Agar-Agar sich rein entwickelt hatten.

Diese Vorexperimente beweisen also: a) dass unser Trypsin Arehiv f. pathol. Anat. Bd. 117. Hft. 3. 
keine Mikroben enthält; b) dass es sich durch Kochen verändert, indem es die Fähigkeit verliert, geronnenes Eiweiss zu verdauen; c) dass es das Wachsthum der Mikroben nicht hindert. In Folge dessen wurden die Versuche mit wässerigen Auflösungen von unsterilisirtem Trypsin ausgeführt.

Typische Experimente. Versuch 46. Am 3. October $11 \mathrm{Ubr}$ Morgens wurde einem Kaninchen $0,5 \mathrm{~g}$ Trypsin in $15 \mathrm{ccm}$ sterilisirten Wassers eingespritzt. Von der Lösung wurde eine Aussaat auf Gelatine und Agar Agar gemacht, welche rein blieb, obne Mikroben. Um 4 Ubr. Nachmittag war das Kaninchen todt. Section gleich nach dem Tode. Die Haare auf dem Bauche rings um den Stich lösten sich büschelweise ab. Das Unterhautzellgewebe erweicht, mit Peptongeruch. Bedentende hämorrhagische Peritonitis. Fast das ganze Peritonảum ist in einen grossen hämorrbagischen Flecken verwandelt, d. h. besetzt mit ungebeuren Extravasaten. Eine bedeutende Quantität hämorrhagischen Exsudates im Peritonäum. Hämorrbagie in den unteren Lungenlappen. Das Herz ist contrabirt, blass. Nieren byperämisch. Das Diaphragma auf beiden Seiten mit Extravasaten besetzt. Die mikroskopische Untersuchung des Exsudates auf Deckgläschen zeigte keine Mikroben, sondern nur Epithelzellen des Peritonäalüberzuges, einzeln oder in Lagen, und hauptsächlich rothe Blutscheiben, weisse in geringer Menge.

Die Züchtung auf Agar-Agar und Platten blieb steril; weder in den Organen, noch in den Wänden des Peritonäum, noch in den Lungen, dem Herzen und den Nieren wurden auf Durchsehnitten Mikroben gefunden.

Versuch 47. Parallel dem vorigen. Tod nach 5 Stunden, mit denselben Sectionsergebnissen und demselben Resultate bei der mikroskopischbakteriologischen Untersuchung.

Versuch 48. Am 7. October. Filtrat von $0,25 \mathrm{~g}$. Trypsin in $7 \mathrm{ccm}$ Wasser. Nach 5 Stunden todt. Section: Peritonitis baemorrbagica. Eine grosse Menge von Extravasaten in Peritonaeum parietale und visserale, Nierenkajsel, Serosa des Magens und Diaphragma u. s. w. Die Milz und Leber vergrössert, Nieren morsch. Im Cavım peritonaei unbedeutendes, aber in beiden Pleurasäcken ein bedeutendes blutiges Fxsudat. Die Lungen sind bedeckt mit kleinen Extravasaten von Mohnsamengrösse. Das Herz welk und morsch. Ueberhaupt wird die Aufmerksamkeit auf einen welken, morsehen, anämischen Zustand aller Organe gelenkt. Das Unterhautgewebe ist durch Trypsin verdaut, es ist ödematös, von schwärzlich grauer Farbe, wie gangränescirt, aber nach Pepton oder frisch gekochtem Ei, riechend. Die Baare lassen sich in Büscheln abbeben. Auf Deckgläschen lassen sich im Exsudate keine Mikroben entdecken, ebensowenig gelang die Züchtung auf Agar-Agar und Platten. Mikroskopisch betrachtet besteht das Exsudat bauptsächlich ans rothen Blutscheiben und einer bedeutenden Quantität von Epithelien aus dem Peritonäalüberzug, theils einzeln, theils zusammenhängend, mit einer nicht geringen Nenge von Leukocyten vermischt. 
Versuch 52. Am 5. October wurden einem Kaninchen $0,1 \mathrm{~g}$ Tryp$\sin$ in $10 \mathrm{ccm}$ Wasser eingespritzt. Am 6. October todt. Section: Mitte]mässige hämorrhagische Peritonitis mit kleinen Extravasaten über das ganze Peritonäum und geringer Menge Exsudates. Im Pleuraraume eine grosse Menge blutigserösen Exsudates. Die Organe sind welk. Mikroben wurden mikroskopisch-bakteriologisch und in Züchtung auf Agar-Agar und Platten nicht gefunden.

Versuch 60. Am 7. Oetober wurden $0,05 \mathrm{~g}$ Trypsin in $7 \mathrm{ccm}$ Wasser eingespritzt. Das Kaninchen blieb am Leben.

Hierdurch ist bewiesen, dass Trypsin ein starker Reizerreger für das Peritonäum ist, welches bei Injection von $0,5 \mathrm{~g}$ in 10 bis $15 \mathrm{ccm}$ Wasser eine intensive hämorrhagische Peritonitis mit hämorrhagischem Exsudate und den Tod bei Kaninchen nach 4 bis $4 \frac{1}{2}$ Stunden erzeugt; $0,25 \mathrm{~g}$ in $7 \mathrm{ccm}$ Wasser, $0,1 \mathrm{~g}$ in $10 \mathrm{ccm}$ Wasser machen eine hämorrhagische Peritonitis und bedingen den Tod nach 20-24 Stunden; nur 0,05 g können die Thiere ertragen. Bei den autopsirten Thieren wurden oben erwähnte Erscheinungen beobachtet, als allgemeine Wirkung des Fermentes: Anämie und Welkheit der Organe, Trennung der Haare in Büschel und des peritonäalen Epithels, Verdaunng des Unterhautgewebes in der Nähe des Stichkanales des Bauches u. s. w. Der Charakter der Peritonitis bleibt ein rein hämorrhagischer, ohne die geringsten Symptome einer Eiterung. Das Exsudat unter dem besteht Mikroskope fast nur aus rothen Blutkörperchen. Mikroben fehlen, sie sind weder mikroskopisch noch in Plattenzüchtung zu entdecken. Zur Vollständigkeit der Versuche über die Wirkung und Rolle chemischer Substanzen auf das Peritonäum, ausser derjenigen des 01. croton. und des Trypsins, war es interessant, die Rolle aufzuklären, welche die chemischen Stoffwechselproducte der Bakterien spielen, also die Einwirkung der Ptomaïne auf das Peritonäum. Diesen Gedanken verwirklichte ich viel später, erst im Laboratorium des Herrn Prof. Pasteur in Paris im Jahre 1888. Zu diesem Zwecke wurde Staphylococcus aureus und Streptococcus erysipelatis in bedeutender Menge auf Kalbsboullion (ungefähr 200-240 ccm) geziichtet und die 4- bis 8 tägige Cultur wurde durch den Filter Chamberland's oder durch ein in einen Kolben gesetztes kleines Porzellanfilter, aus welchem ersteren die Luft mit einer Quecksilberpumpe ausgepumpt wird (Pasteur's Filter), filtrirt. Das kalte, auf Agar- 
Agar und Bouillon gesäte und auf allen Nährsubstraten stets steril bleibende Filtrat wurde aus einem besonderen gläsernen Apparate von Roux (ähnlich dem oben beschriebenen für $0 l$. crot.) in das Peritonäum von Meerschweinchen in der Quantität von $15-30 \mathrm{ccm}$ eingespritzt.

Versuche. Am 17. Februar wurden $30 \mathrm{ccm}$ Filtrat einer 8 tägigen Bouilloncultur von Staphylococcus aureus einem ausgewachsenen Meerschweinchen eingespritzt. Am 18. todt. Section: Im Peritonäum eine grosse Qnantität blutiger Flüssigkeit. Die Serosa des Magens und der Gedärme roth, bedeckt mit kleinen Extravasaten. Das Exsudat besteht hauptsächlich aus rothen Blutkörperchen. Eiterelemente oder Mikroben sind nicht vorhanden. Die Aussaaten auf Agar-Agar und Bouillon blieben steril.

21. Februar. Vier Meerschweinchen wurde das kalte Filtrat einer viertägigen Bouilloncultur von Staph. aur. in das Peritonäum eingespritzt. Z weien $20 \mathrm{ccm}$ und zweien $15 \mathrm{ccm}$. Am 22. sind alle todt. Seetion: Intensive Injection der Serosa, der Gedärme und des Peritonäums. Eine grosse Menge serös-hämorrhagischen Exsudates, unter dem Mikroskope hauptsächlich aus rothen Blutkörperchen bestebend. Eiterelemente und Mikroben weder im Exsudate, noch in Culturen auf Agar-Agar und Bouillon zu entdecken.

6. Februar 1888. Zweien Meerschweinchen wurden $15 \mathrm{ccm}$ einer viertägigen Bouilloncultur von Streptococcus erysipelatis, 15 Minuten bei $115^{\circ}$ im Autoklav sterilisirt, eingesprizt. Am 7. Februar sind die Thiere munter. Am 9. wurden sie durch Chloroform getödtet. Im Peritonäum keine Verănderungen.

8. Februar. Kinem Meerschweinchen wurden $15 \mathrm{ccm}$, einem anderen $20 \mathrm{ccm}$ eines kalten Filtrates einer fünftägigen Streptococcus erysip. Bouilloncultur eingespritzt. Am 9. sind die Thiere munter, am 11. wurden sie getödtet. Im Peritonäum keine Erscheinungen.

Somit hatten auch diese Versuche mit dem kalten Filtrate pathogener Mikroben zwei verschiedene Resultate:

Auf der einen Seite wurde es klar, dass, wenn auch chemische Substanzen - Ptomaïne - einer Cultur von Staph. aur. allein, ohne Mikroben, starke Reizerreger sind, welche in einer Quantität von $15 \mathrm{ccm}$ den Tod von Meerschweinchen nach 24 Stunden herbeiführen, der Charakter des Prozesses hier doch hämorrhagisch bleibt, wie auch in den vorhergehenden zwei Reihen von Versuchen. Auf der anderen Seite blieb das Filtrat des Streptoc. erysip. ohne Wirkung auf das Peritonäum und wurde von den Thieren gut ertragen. Mit einem Worte: Erscheinungen einer Peritonitis purulenta beobachteten wir in 
keiner der vier Reihen von Beobachtungen mit Injection chemischer Substanzen in die Bauchhöhle ${ }^{1}$ ).

Auf Grund dieser 3. Reihen von Experimenten mass ich mich gegen die Vertheidiger der Ansicht, dass chemische Sub-

1) Ich erlaube mir hinzuzufügen, dass meine oben angeführten Versuche mit 0l. croton., Trypsin und dem kalten Filtrate von Staphyl. aur. und Streptococcus erysipelatosus eine directe Beziehung haben zur heutigen Lehre von der Ursache der Eiterung. Ol. croton. wird von manchen Autoren für fähig gehalten, Eiter bei Thieren zu erzeugen. Auf Grund oben mitgetheilter Versuche und der Resultate der bakteriologischen Untersuchung muss ich es entschieden aussprechen, dass Einspritzung von Oleum crotonis keine Eiterung hervorlief. Mit Trypsin als einem starken Reizerreger des Peritonäums wurde bisher noch nicht experimentirt zur Bearbeitung der Lebre von den Ursachen der Fiterung. Die durch wich erhaltenen Ergebnisse sprechen dafür, dass der Charakter der Entzündung* durch Einspritzung von Trypsin in das Peritonäum ebenfalls rein hämorrhagisch bleibt, ohne die geringste Andeutung einer Eiterung. Grawitz spritzte Ptomain ein, welches er von Brieger aus Culturen von Staphylococeus aureus erhielt, und bebauptet von Neuem, dass dieses Ptomaīn Eiterung hervorrufen kann. Meine Versuche über die Wirkung des Filtrates aus Staph. aureus sprechen gegen seine Ergebnisse. Der Charakter der Entzündung, wie sie durch dieses Filtrat im Peritonäum hervorgerufen wird, ist auch nur hämorrhagisch und nicht eiterig. Indem mich die Arbejten von Grawitz mit ibren Resultaten und seinen Behauptungen äusserst interessirten, setzte ich später in Pasteur's Laboratorium meine Experimente mit dem Filtrate des Staphyl. aureus fort. Am 24. Februar 1888 spritzte ich zweien Meerschweinchen an drei Stellen unter die Haut je eine Pravaz'schen Spritze eines kalten Filtrates von Staphyl. aureus und wiederbolte die Injection am 27. Februar. Am 28. wurde dieselbe noch einmal wiederholt und ich beobachtete nur die Bildung von trockenen Krusten an den Stellen der Injection; weder Eiterung noch Eiterbeerde wurden gefunden. Mikroben waren auch nicht vorhanden, weder bei der mikroskopischen Untersuchung auf Deckgläschen, noch bei der Züchtung auf Agar-Agar und Bouillon. Ferner wurde am 27. Februar zweien Kaninchen in die vordere Augenkammer jedem $0,3 \mathrm{ccm}$ eines kalten Filtrates von Staphyl. aureus gespritzt. Am anderen Tage wurden in den Augen leicbte Trübung und fibrinöse Flocken bemerkt. Nach einer Woche, am 7. März, wurden die Augen exstirpirt und abermals wurden in den vorderen Augenkammern weder bei der mikroskopischen, noch bei der bakteriologischen Untersuchung die geringste Andeutung einer Eiterung oder Mikroben entdeckt. 
stanzen Eitererreger seien, aussprechen und mich zu den Anhängern der Ansicht bekennen, dass „ohne Mikroben - keine Eiterung".

Ganz andere Erscheinungen wurden in der zweiten Reihe der Versuche beobachtet in Bezug auf die Wirkung der verschiedenen Mikroben auf das Peritonäum. Sie wurden in allen unseren Versuchen mit allen oben beschriebenen Vorsichtsmaassregeln, gewöhnlich in $7 \mathrm{ccm}$ Wasser (dem Gehalt der Spritze) aus frischen Plattenreinculturen eingespritzt.

Im gewöhnlichen Leben und in der Praxis, bei Verwundungen oder Operationen am Peritonäum können in diese Höhle Mikroben zweier verschiedener Arten fallen: nicht pathogene und pathogene. Die Klarstellung dieser und jener ist äusserst interessant, für die Theorie ebensowohl als auch für die Praxis. Mit den ersteren, den nicht pathogenen Mikroben sind bis jetzt keine regelrechten Experimente ausgeführt worden, mit Ausnahme von Wegner's Injectionen mit einer Mischung verschiedener unbekannter Mikroben in fauler Flüssigkeit. Mit den letzteren, den pathogenen, hat auch ausser Grawitz Niemand experimentirt; seine interessanten Resultate fordern sehr zu einer Wiederholung auf.

Wir nahmen deshalb zuerst Versuche mit nicht pathogenen Mikroben vor. Aus dem Eiter einer acuten Osteomyelitis, welcher zunächst in einem nicht exact sterilisirten Eiterbecken aufgefangen war, wurde auf Platten ein Mikrob gezüchtet, welches dem Aeusseren nach, unter dem Mikroskope und auf Agarculturen, gleich war dem Staphylococcus aureus. Im Anfange wurde es für diesen gehalten; in der Folge zeigte sich, dass es nicht pathogen war und Gelatine nicht verflüssigte. Dieses Mikrob wurde in grossen Quantitäten eingespritzt, 1-2 Agarculturen, theils allein, theils mit Oleum crotonis. Das letztere wurde in einer Quantität hinzugefügt, wie sie von den Thieren ohne Schaden vertragen wird ( $\frac{1}{30}$ Tropfen). Ein anderes nicht pathogenes Mikrob, von uns eingespritzt, war gelbe Sarcine. Dieses Mikrob wurde mit $\frac{1}{10}$ Tropfen Ol. crot. - unschädliche Quantität für Thiere (s. die Versuche mit 0l. srot.) - eingespritzt. Es wurden 7 Versuche gemacht, 6 mit Kaninchen, einer mit einem Hunde. 
Versuch No. 9. Am 3. August wurde einem Kaninchen mittlerer Grösse eine volle Spritze $(7 \mathrm{ccm})$ sterilisirten Wassers mit einer in ibr suspendirten 7 tägigen Cultur von diesen, dem Staphyl. albus ähnlichen Kokken injicirt. Das Kaninchen blieb gesund und munter.

Versuch 10. Am 9. August. Parallel dem vorigen. Eingespritzt eine 3tägige Cultur desselben Coccus in zwei Spritzen Wasser. 10. August: Das Kaninchen ist munter, frisst gut. Blieb am Leben.

Versuch 16. Am 17. August wurden einer schwarzen Hündin mittlerer Grösse zwei 17 tägige Agarculturen des oben beschriebenen weissen Coccus mit einer Spritze Wassers injicirt. Der Hund war am 18. August munter und gesund, ebenso am 28, und blieb am Leben.

Versuch 18 und 19. Am 18. August wurde 2 Kaninchen je 1 Spritze einer 18 tägigen Agarcultur weisser Kokken eingespritzt, in einer Spritze Wasser mit $3^{1} \overline{0}$ Tropfen Ol. crot. ( $1 \mathrm{ccm}$ Emulsion ans: Ol. crot. git. ij, Mucilag. gummi arabici 1,0, Aq. dest. 59,0). 21. August: beide munter, blieben am Leben.

Versuch 34 und 35, mit gelber Sarcine. Am 26. September. 2 Kaninchen wurden 2 Platinöhsen von Agarculturen gelber Sarcine mit $\frac{1}{10}$ Tropfen Ol. croton. (in oben erwähnter Emulsion) in einer Spritze voll Wasser injicirt. Beide Kaninchen blieben am Leben.

Diese Experimente mit nicht pathogenen Kokken gaben ein änsserst lehrreiches Resultat. Es zeigte sich, dass diese Mikroben, einerlei ob sie in grossen Quantitäten oder vermischt mit chemischen Reizerregern eingespritzt, keine Peritonitis bei den Thieren erzeugen. Zugleich beweisen sie, wie leicht man nichtpathogene mit pathogenen Mikroben verwechseln kann, während man mit den ersteren experimentirt, die Resultate der Versuche auf Rechnung der letzteren setzt. Endlich sind sie für uns von besonderem Interesse, indem diese Versuche als Controlversuche und als Garantie dienten, dass unsere Mittel genügten, eine unabsichtliche Infection auszuschliessen.

Wir werden jetzt zu den Resultaten der Versuche mit pathogenen Mikroben übergehen und nach deren Injection in das Peritonäum ganz neue, den oben beschriebenen nicht gleiche Prozesse finden, und zwar: eine Reihe reiner Infectionsperitonitiden mit charakteristischem Verlaufe und ausgeprägten pathologisch-anatomischen Erscheinungen.

Im Ganzen wurden hier drei Reihen von Versuchen mit drei verschiedenen Species von Bakterien unternommen. Da ich danach strebte, eine Peritonitis purulenta hervorzubringen, so ex- 
perimentirte ich vor allen Dingen zuerst mit Staphyl. aureus, als dem am meisten typischen, dem viruleutesten der pyogenen Mikroben. Culturen des letzteren wurden durch Plattenzüchtung aus Knochenmarkeiter gewonnen bei einer, durch Osteomyelitis acuta nöthig gewordenen Osteotomie mit Ausschabung der Knochenmarkhöhle. Von 41 Experimenten mit Staphylococcus aureus wurden $1 \dot{7}$ mit ihm allein, 11 mit Staphyl. aur. und 0l. croton., 6 mit Staphyl. aur. und Trypsin und 7 mit Staphyl. aur. und Agar-Agar gemacht.

Die Versuche mit Staphyl. aur. zerfallen in 7 Reihen von der Injection grosser Quantitäten bis zu der minimaler. Zunächst wurde nach der Angabe von Grawitz in vielen dieser Versuche mit grossen Quantitäten gearbeitet, was sich später als ganz überflüssig zeigte. Hier mögen die typischen Experimente angeführt werden. Die übrigen sind in der beigefügten Tafel aufgeführt.

1. Grosse Mengen (Agarcultar von Staphylococcus aureus in 1-2 Spritzen Wasser).

Versuch 11 und 12. An 13. August wurde eine 13tägjge Agarcultur von Staphyl. aureus mit 2 Spritzen Wassers injicirt. Am 14. August todt. Section: Allgemeine fibrinöse Peritonitis. Fibrinflocken, welche sich leicht in dünnen Lamellen abbeben lassen, bedecken alle Gedärme. Die Serosa injicirt. Ein flüssiges Exsudat ist nicht vorhanden. In Deckglaspräparaten sind nur Staphylokokken zu seben. Auf Platten und in Aussaat in Reagenzröbrehen nach $\mathbb{E}$ smarch entwickelten sich Colonien nur von Staphyl. aureus.

Versuch 56. Am 6. October eine lotägige Agarcuitur von Staphyl. aur. mit einer Spritze Wasser. Am 8. October todt. Im Peritonäum kein Exsudat und keine besonderen Veränderungen. Sehr kleine und seltene Fibrinfiocken, Milz vergrössert, Nieren morsch, das Gewebe gran, mit keilförmigen Infarcten. Herzmuskel welk, durchsetzt von Hämorrhagien, stellenweise gelb; Intima und die ganze Valvula tricuspidalis durchsetzt mit Extravasaten. Jungen hyperämisch, wegsam. In Deckglaspräparaten und Plattenzüchtung Mikroben in geringer Menge. Tod an Peritonitis mycotica.

Versuch 55. Am 6. October. Ein dem vorigen paralleler Versuch. Tod nach 8 Tagen. Section: Eitrige Peritonitis wit grossen Eiteransammlungen zwischen Leber und vorderer Brustwand, ebenso an verscbiedenen Stellen zwischen Mesenterium und Gedärmen. Sehr viele embolische, eitrige Heerde in den Nieren von der Grösse eines Hirsekornes bis zu der eines Mohnsamens und eitrige keilförmige Infarcte. In der Leber embolische Heerde von der Grösse einer Erbse und zwei embolische Heerde in der Spitze des Herzens. 
Die Milz ist vergrössert. In Declsglaspräparaten Staphylococcus aurens. Tod an Peritonitis purulenta und Pyaemia.

Versuch 76. Am 13. October. Einem schwarzen Hunde von mittlerer Grösse wurde eine 3tägige Agarcultur von Staphylococcus aureus mit einer Spritze Wassers injicirt. 15. October: der Hund ist krank, kann nicht gehen, wankt in Steben, ist traurig, frisst nicht, der Räcken gekrümmt. Tod am 23. October. Section am 24. Sehr starke Hyperämie des Peritonäums und kleine Extravasate in Netze. Auf dem Nesenterium und der vorderen Bauchwand eine nicht unbedeutende Menge trüben, sogenannten katarrłalischen Exsudates. Unter dem Mikroskope besteht das Exsudat nur aus Eiterkörperchen, Staphylokokken und auderen Bakterienformen. (Der Hund wurde nach 24 Stunden secirt.) Auf Platten entwickelten sich Staphylokokken und andere Formen ron Mikroben. Auf Querschnitten fanden sich Staphylokokken in den Lymphspalten des Centrum tendineum. Tod an Peritonitis purulenta et baemorrhagica (incipiens).

Versuch 77. Am 13. October. Parallel dem vorigen. Tod nach 20 Stunden. Das Peritonäum ist bedeckt mit kleinen Extravasaten und eben solchen fibrinösen Flocken. In der Bauchhöhle eine ziemlich grosse Menge hämorhagischen Exsudates. Unter dem Mikroskope besteht dasselbe aus rothen Blutkörperchen und einer Menge von Eiterkörpercben und Staphylokokken. Die letzteren wurden auch auf Durchschnitten im Centrum tendinosum und Peritonaeum parietale gefunden.

2. Mittlere Menge. 2 Platinöhsen ${ }^{1}$ ) mit Staphylokokkencultur in einer Spritze Wasser.

Versuch 69. Am 11. October wurden 2 Platinöhsen mit Staphyl. aureus aus einer 3wöchentlichen Agarcultur eingesprizt. Tor am 12. October. Section: Das ganze Peritonäum ist byperämisch, mit kJeinen Fibrinflocken und einer fadenziebendon Flüssigkeit bedeckt, welche unter derw Mikroskope ausschliesslich aus den eingespritzten Mikroben besteht. Eine grosse Quantität batarrbalischen flüssigen trüben Exsudates unter dem Mikroskope, hauptsächlich aus Eiterkörperchen und Staphylokokken zusammengesetzt. Leber und $\mathrm{Milz}$ vergrössert und morsch. Iu der Pleurahöhle ein ebensolches Exsudat, wie in dem Peritonäum, in bedeutender Quantität. A uf Agarplattenzüchtung entwickelten sich nur gelbe Staphylokokzen. Tod an Peritonitis purulenta incipiens.

Versuch 70. Am 11. October. Ein dern vorigen paralleles Experiment. Tod am 12. October, Im Peritonäum eine ergiebige Menge durchsichtiger, blutiger Flüssigkeit. Auf der Serosa nur Hyperämie. Extravasate und

1) Indem wir in dieser Arbeit zur Abkürzung die Ausdrücke benutzen: 2 Platinöhsen, $\frac{1}{4}$ Platinöhsen u. s. f., verstehen wir darunter die natürlich noch sehr verscbiedene Menge der Mikroben in Agarcultur, welche in einer kleinen Platinöhse enthalten sein können. 
Flocken nicht zu sehen. In Deekglaspräparaten und solchen auf Platten Staphylococcus aureus in Reincultur. Tod an Peritonitis acuta exsudativa haemorrhagica.

Versuch 74. Am 13. October dieselbe Quantität eingespritzt, wie im Versuch 69. Am 14. October todt. Section: Im Peritonäum auf der Serosa der Gedärme sind keine besonders bemerkbaren Veränderungen zu sehen, ausser Hyperämie. Die Gedärme sind mit einer charakteristischen schleimiger Flüssigkeit bedeckt, welcbe sich in unbedeutender Menge in den tieferen Stellen des Peritonäums, wie ein opalescirendes Exsudat aussebend, ansammelt. Die Milz ist vergrössert, die Nieren hypertrophisch. In der Pleura ist die Menge durchsichtigen Exsudates etwas grösser als im Peritonäum. In Präparaten auf Deckgläschen besteht die schleimige Flüssigkeit, welche die Gedärme äberziebt, ausscbliesslich aus Mikroben, unbedeutend mit Eiterkörperchen vèrmischt. Auf Plattenzüchtung entwickelten sich nur Stapbylokokken. Tod an Peritonitis mycotica.

Versuch 75. Am 13. Octocer. Parallel dem vorigen. Bei der Section dieselben Erscheinungen. Das Exsudat besteht bauptsächlich aus Mikroben, vermischt mit Eiterelementen und Endothelzellen. Auf Platten wurden Staphylokokken erhalten. Auf Durchschnitten, nach Gram gefärbt, im Centrum tendineum und in Lymphspalten des Peritonaeum parietale wurden eben solcbe Mikroben gefunden; grössere Massen der letzteren waren von einer starken Schaar von Eiterelementen und farblosen Blutkörperchen umgeben. Aber Mikroben wurden auch über das Infiltrat hinaus, in der Tiefe des Gewebes gefunden.

3. Kleine Quantitäten (1 Platinöhse wurde mit einer Spritze Wassers durch eine Lage sterilisirten Papiers filtrirt).

Versuch 85. Am 18. October. Die erwähnte Quantität von Mikroben wurde vor der Einspritzung auf Mikroben untersucht; im Filtrate ist eine Masse Staphylokokken zu sehen; und auf Agar-Agar geimpft entwickelten sie sich in dichter Reihe. Am 18. October Injection. Am 19. todt. Die Gedälme sind mit fibrinösem Exsudat bedeckt. Im Peritonäum befindet sich eine grosse Quantität trüben, sogenannt katarrhalischen Exsudates. Hyperämie der Serosa des Darmes, die Milz vergrössert. Unter dem Mikroskop besteht das Exsudat aus Eiterkörperchen und Staphylokokken. Auf Durchschnitten wurden die letzteren nach Gram in den Lymphspalten des Centrum tendineum und im Peritonaeum parietale gefunden (Fig. 1 und 2). In Plattenculturen entwickelte sich Staph. aureus.

4. Ganz kleine Quantitäten (1 Platinöhse: $5 \mathrm{ccm}$ Wasser, davon $1 \mathrm{ccm}$ auf die Spritze Wasser).

Versuch 78. Am 17. October Injection oben erwähnter Menge von Hikroben. A w 18. October des Morgens sterbend, nach wenigen Minuten todt. Section augenblicklich. Grosse Fibrinflocken auf dem Dickdarme. Andere 
Theile des Darmes stark hyperämisch und mit schleimigem Exsudate bedeckt, welchen zu sammeln nicht gelang. In der Nähe der rechten Niere und der Leber kleine Eiterheerde. Die Milz ist vergrössert. In der Pleura eine unbedeutende Menge durchsichtigen, serösen Exsudates. Auf Deckglaspräparaten eine Masse Eiterkörperchen und Staphylokokken in Reincultur. Die Mikroben durchuringen auch die Fibrinflocken. Auf Durchschnitten wurden sie in Lymphräumen des Mesenteriums nachgewiesen. In Plattenculturen in Agar entwickelten sich nur gelbe Staphylokokken. Tod an Peritonitis fibrinosa purulenta incipiens.

Versuch 79. Am 17. August. Parallel dem vorigen. Todt am 18. Dieselben Resultate der Section und der bakteriologischen Untersuchung.

5. Filtrat aus der oben angegebenen Quantität.

Versuch 86. Am 19. October Injection. Am 20. todt. Section. Einige Flocken auf den Gedärmen und der Pars pylorica des Magens. Nili dunkel gefärbt, vergrössert. Hyperämie der Gefässe des Mesenteriums, charakteristische schleimige Flüssigkeit im Peritonäum in unbedentender Menge. Eine Platinöbse von dieser Flüssigkeit von der Oberfläche des Darmes unter das Mikroskop gebracht, zeigt als Hauptbestandtheil Staphylokokken mit einer geringen Beimischung von Eiterelementen. Eine Plattencultur entwickelt nur gelbe Staphylokokken. Tod an Peritonitis mycotica.

6. Minimalmenge (2 Platinöhsen auf 5 ccm Wassers, filtrirt; von dem Filtrate 2 Platinöhsen auf eine Spritze Wassers).

Versuch 87. Am 19. October. 'Tod am 1. November, also nach 12 Tagen. Eitrige Peritonitis, mit einer ungehenren Menge flüssigen, theils freien, theils die Gedärme und das Omentum verklebenden eitrigen Exsudates im Peritonäum. Die Milz ist vergrössert; in der Pleura undurchsichtiges seröses Exsudat. In Präparaten aus dem Exsudate und auf Plattenculturen wurden Staphylokokken erhalten.

7. Die Hälfte der oben erwähnten Quantität (eine Platinöhse 5 ccm Wasser filtrirt, davon 2 Platinöbsen auf eine Spritze). Zwei zum Experimente benutzte Kaninchen blieben am Leben.

Aus obigen Experimenten ist ersichtlich, dass der Staphylococcus aureus für das Peritonäum leider ein äusserst giftiges Agens ișt. Geleitet von der Behauptung von Grawit\%, dass man viele Millionen pyogener Mikroben ohne Nachtheil den Thieren einspritzen könne, begannen wir unsere Versuche mit Injectionen grosser-Mengen Mikroben und erhielten einen raschen Tod durch Peritonitis. Wir verminderten das Injectionsmaterial bis zu zwei Platinöhsen voll Staphylokokken aus Agarcultur; eine acute Peritonitis blieb als unveränderliches Resultat. Indem wir weiter 
die Dosen der einzuspritzenden Staphylokokkencultur verminderten, sahen wir, dass eine Platinöhse voll von Staphylokokken - $\frac{1}{5}$ dieser Quantität - das Filtrat aus dieser letzteren Quantität und sogar 2 Platinöhsen von dem Filtrate der 2 Platinöhsen, die Kaninchen ebenfalls rasch durch dieselbe Krankheit tödten. Nach langer Anstrengung fanden wir endlich jenes Minimum: die Hälfte der letzten Minimaldose, welche die Thiere ertragen, ohne zu sterben.

Bis auf Weiteres vermeide ich, eine Erklärung der Differenz zwischen meinen und Grawitz Vèrsuchen zu geben. Dazu führt keine Discussion betreffs der Auslegung der beiderseits gleich sorgfältig ausgeführten Versuche, sondern nur neue Gesichtspunkte, welche die weitere Arbeit erbringen wird.

Unsere Versuche erhärten vollständig die Ansicht Wegner's in Bezug auf das Peritonäum als eine Höhle. Es genügt, eine minimale Menge gelber Staphylokokken dem Thiere einzuspritzen, um seinen Tod zu verursachen. Unsere Versuche befinden sich ausserdem in vollständiger Harmonie mit den Eigenschaften des Peritonäum als thierischer Membran und mit den biolugischen Eigenthümlichkeiten der gelben Staphylokokken. Wenn dieses Mikrob äusserst giftig auf alle bestehenden weichen Gewebe wirkt, so muss es ebenso giftig sein für das Peritonäum als ein organisches Gewebe, welches den allgemeinen Bedingungen und Gesetzen des Lebens sowohl als auch der Zerstörung unterworfen ist. Analysiren wir weiter diese Versuche, so finden wir, dass der Staphyl. aureus die wahre Ursache der acuten eitrigen Peritonitis ist. Aus der Reihe oben angeführter Experimente mit verschiedenen Mengen dieses Mikroben ist ersichtlich, dass, je grösser die Menge der eingespritzten Mikroben, desto rascher der Tod der 'Thiere, und zwar so, dass vom Augenblicke der Einspritzung bis zum Tode die Zeit zu kurz war, um ein vollständiges Bild der Eiterung zu liefern. Bei den Thieren, welche nach einer Injection mit grosser Menge in den ersten Stunden oder Tagen zu Grunde gingen, wurde eine fibrinöshämorrhagische oder eine fibrinös-katarrhalische Peritonitis beobachtet. Im ersten Falle wird im hämorrhagischen Exsudate schon in dieser Zeit eine bedeutende Menge von Eiterkörperchen neben den injicirten Mikroben in Reincultur beobachtet. Im 
zweiten Falle, in der fibrinös-katarrhalischen Form, ist das flüssige Exsudat trübe und ganz gleich dem katarhalischen Exsudate, z. B. bei Gelenkentzündung. Unter dem Mikroskope aber besteht es aus den eingespritzten Mikroben und einer Masse von Eiterelementen. Wir halten den Ausdruck "katarrhalisch" für das Exsudat dem Wesen und dem Charakter der Entzündung nicht entsprechend. Das katarrhalische Exsudat bei Peritonitis acuta ist die erste Phasis der eitrigen Peritonitis, und eine Peritonitis mit solchem Exsudate ist eine Peritonitis purulenta incipiens.

Bei längerer Lebensdauer des Thieres von mehr als einem Tage - bis zu 2-3 Tagen, tritt der eitrige Charaker der Peritonitis immer mehr hervor. Auf verschiedenen Stellen des Peritonäums, zwischen den Gedärmen, erscheinen Heerde mit typischem dickem Eiter. Die Eiteransammlungen vergrössern sich immer mehr, umkleiden den Darm, - im Peritonäalraume sammeln sich ungeheure Massen flüssigen Eiters an, und - wenn das Thier einige Tage lebt, eine $W_{0}$ che - so entwickelt sich nicht selten, ausser eitriger Peritonitis, eine typische Pyämie mit Metastasen und charakteristischen eitrigen Embolien von Staphylococcus aureus in den verschiedenen inneren Organen (s. Versuche $55,56,87)^{1}$ ).

1) Wir sind tief überzeugt, dass in der bei weitem grössten Mehrzahl die Ursacbe der Peritonitis der Staphylococcus aureus ist in früher von uns veröffentlichten 5 Fällen von Pyämie erhielten wir aus metastatischen Eiterheerden innerer Organe auf Platten und unter dem Mikroskop gelbe Staphylokokken in Reincultur (Centralbl. für die med. Wissensch. No. 24 u. 25, 1887 und Puckaja medizina No. 3, 1887). Oben angeführte Experimente sprechen noch einmal deutlich für die Ricbtigkeit der von uns aufgestellten Ansicht. Nach Einbringen in das Peritonäum (wie auch in unseren früher veröffentlichten Versuchen mit Einspritzung des Staphylococcus aureus in's Blut), bei während einiger Tage dauerndem Leben des Thieres ruft der Staphylococcus aurens bei Kaninchen eine typische Pyämie hervor. Deshalb wird es sachgemäss sein, Panaritium, Phlegmone, Osteomyelitis acuta, Peritonitis purulenta und Pyämie nach ibrer ätiologischen Wesenheit als gleiche Krankheiten zu betrachten. Der Unterschied zwischen ihnen besteht nur in der Entwickelung, in dem Grade des Prozesses, d. b. er ist ein quantitativer, aber kein qualitativer. 
Sehr interessante Formen von Peritonitis wurden in einigen Versuchen bei Thieren beobachtet, welche am ersten Tage starben. Ungeachtet des raschen Todes konnten im Cavum peritonaei fast gar keine besonderen pathologisch-anatomischen Veränderungen nachgewiesen werden, ausser einer leichten Hyperämie der Darmserosa und zuweilen einigen kleinen Fibrinflocken (s. Versuche No. 74, 75 a. 86). Im Cavum peritonaei aber befand sich zuweilen eine charakteristische, klebrige, schleimige Flüssigkeit. Beim ersten Anblicke erschien das Peritonäum ganz normal und die Ursache des Todes war unklar und nicht zu erklären; aber man hatte nur mit der Platinöhse über die Oberfläche der Gedärme zu fahren und ein Deckglaspräparat zu machen, um unter dem Mikroskope eine Masse von Staphylokokken zu sehen. Man hatte nur die Platinöhse in die klebrige, schleimige Flüssigkeit zu tauchen, um sich durch das Mikroskop zu überzeugen, dass sie fast ausschliesslich nur aus Mikroben bestand. Auf Durchschnitten befanden sich in den Lymphspalten und in der Wandung des Peritonäums in diesen Fällen ebenfalls dieselben Mikroben. Wir hatten es also mit einer Form von Peritonitis mycotica $z u$ thun, welche bis jetzt weder experimentell noch am Krankenbette beobachtet wurde.

Trotzdem existirt eine solche Peritonitis und durch sie lässt sich eine Reihe von Fällen rasch erfolgten Todes erklären, welche nach Laparotomien, Perforationen, kleinen Rupturen der Gedärme auftreten, in Fällen, in welchen gar keine deutlich ausgesprochene Erscheinung einer Peritonitis gefunden wird. Durch das Bestehen einer bakteriellen Peritonitis lassen sich auch einige Todesfälle von sogenanntem Shock erklären. In der Folge werden wir noch hin und wieder dieser Form der Peritonitis begegnen.

Ausser den oben erwähuten Gruppen von Experimenten wurden von uns im Anfange einige Versuche ausgeführt mit Einspritzung grosser Quantitäten von Staphylococeus aureus allein, dann mit Trypsin und auch mit 0l, ćrotonis. Alle Thiere gingen natürlich $z u$ Grunde an verschiedenen Formen von Peritonitis acuta. Diese Versuche haben, in Anbetracht der zerstörenden Wirkung minimaler Menge allein von Staphyl. aureus, keine besondere 
Bedentung, und einige von ihnen werden in dem allgemeinen Register der Experimente kurz angeführt werden.

Bei jedem Experimente wurden auf Deckgläsern Staphylokokken in Reincultur gefunden und im Exsudate Eiterkörperchen. Bei Sectionen rasch nach dem Tode des Thieres brachte Aussaat auf Agar-Agar in allen Fällen Staphylococcus in Reincultur hervor. Wenn aber die Section einige Stunden oder nach einem Tage ausgeführt wurde, so wurden im Peritonäum ebenfalls secundär aus dem Darme ausgetretene Mikroben beobachtet.

In dünnen, mit dem Mikrotom bereiteten Durchschnitten aus festen und eingebetteten Geweben, nach verschiedenen Methoden von Löffler gefärbt und nach einer von mir modificirten Weise durch Methylenblau, mit Entfärbung der Schnitte auf dem Objectglas durch schwache Alkohollösung von Bismarkbraun, wurden Staphylokokken in den Organen, in den Lymphspalten des Centrum tendineum (s. F. 1), im Peritonäum der vorderen Bauchwand (s. F. 2) und in der Kapsel, den Trabekeln und oberflächlichen Pulpalagen der Milz constatirt.

So bin ich denn auf Grund dieser Versuche zu einem entgegengesetzten Schlusse gekommen, wie Grawitz, und zwar: dass der Staphylococcus aureus in unbedentender Menge bei Kaninchen eine tödtiche acute Peritonitis hervorruft und dass je länger die Thiere leben, desto deutlicher der purulente Charakter dieser Peritonitis hervortritt.

Da der Staph. aur. zu der Gruppe der pyogenen Mikroben gehört, so mussten die mit demselben gewonnenen Resultate auch unumgänglicher Weise die Frage nach der Wirkung der übrigen pyogenen Mikroben aufwecken. Es musste entschieden werden, ob der Staphyl. aur. die alleinige Ursache der acuten eitrigen Peritonitis ist, oder ob auch die übrigen pyogenen Mikroben ebenso virulent für das Peritonäum sind. In Folge dessen warde in den folgenden Versuchen der Bacillus pyocyaneus genommen, einestheils, weil er oft bei Eiterung gefunden wird, anderentheils, weil er als ein friedsamer Ansiedler im Eiter betrachtet wird, also als eine Species pyogener Mikroben von besonders schwacher Virulenz. 


\section{8}

In der Literatur hat sich die Meinung geltend gemacht, dass der Bacillus des blauen Eiters nicht pathogen sei ${ }^{1}$ ), während meine Versuche mich zum entgegengesetzten Resultate geführt haben.

Versuch 53. Am 6. October warde eine 2tägige Agarcultur des Bacillus pyocyaneus in $9 \mathrm{ccm}$ Wasser eingespritzt. Tod am 9 . October. Section. Hyperaemia peritonaei, kleine fibrinöse Flocken auf Milz und Leber. Geringe Menge blutig-katarrhalischen Exsudats im Peritonäum. Hyperämie der Nieren. Das Herz ist mit Blut gefüllt. In Präparaten aus dem Exsudate besteht das letztere aus den Bacillen des blauen Eiters in Reincultur, aus rothen und wenigen weissen Blutbörperchen. Auf Platten wurden nur Bácilli pyocyanei erhalten. Tod. - Peritonitis fibrinosa-haemorrhagica.

Versucb 54. Am 6. October. Parallelversucb zu dem vorigen. Am 9. October todt. Die Gedärme, Milz und Leber sind mit kleinen Fibrinflocken bekleidet. Im Peritonäalraume eine ziemlich grosse Menge blutigkatarrhalischen Exsudates. Nieren und Leber morsch, Milz vergrössert. Herz mit Blut gefüllt. Lungen blass, wegsam. Unter dem Mikroskop sieht man im Exsudate rothe Blutkörperchen, Bacillen und zuweilen Eiterelemente. Auf Platten entwickelte sich nur Bacillus pyocyaneus. Tod an Peritonitis fibrinosa-haemorrhagica. Auf Durchschnitten, mit wässriger Lösung von Metbylenblau gefärbt, (Bacillus pyocyaneus färbt sich nicht nacb Gram) wurden in den Organen Bacillen in grosser Menge gefunden, so in dem Bindegewebe der-Nieren, in den Harnkanälchen, in den Bindegevebsspalten des Diaphragma, in der Kapsel der Leber und Milz. Yon der Kapsel der letzteren verbreiteten sie sich in die Tiefe den Trabekeln entlang, drangen übrigens nicht bis zum Centrum vor.

Versuch 61. Am 8. October wurden 2 Platinöbsen einer 2tägigen Agarcultur von Bacillus pyocyaneus mit einer Spritze Wasser eingespritzt. Tod am 9. October. Section. Hyperämie des Peritonänm, kleine Fibrinflocken auf Gedärmen, Mil und Leber. Die Gedärme sind ausserdem mit einer schleimigen, klebrigen und fadenziehenden Flüssigkeit überzogen, aber in der Peritonäalhöhle befindet sich eine geringe Menge dunkelrothen Exsudates. Unter dem Mikroskop besteht es aus rothen Blutkörperchen und aus einer ungeheuren Menge von Bacillen des blauen Eiters. Die schleimige Flüssigkeit besteht unter dem Mikroskope ausschliesslich aus den eingespritzten Bacillen. Auf Platten erschien Bacillus pyocyaneus in Reincultur. Tod an Peritonitis fibrinoso-haemorrhagica.

Versuch 62. Parallelversuch zn dem vorigen am 8. October. Tod am 11. October. Section. Dje Gedärme durch viele breite Häutchen um den Injectionspunkt verklebt, ibre Serosa mit kleinen Hämorrhagien besäet. In

I) K. Fränkel, Grundriss d. Bakterienkunde. Berlin 1887. S. 327. Flügge, Die Mikroorganismen. 2. Aufl. Leipzig 1886. S. 287. 
den übrigen Theilen ist das Peritonäum byperämisch. Die Hilz ist stark vergrössert, die Nieren welk, blass und stellenweise mit gelben Punkten besetzt. Auf der Leber viele Fibrinflocken, ebenso am Pericardium. Im Endocardium Hämorrbagien. Im Cavum peritonaei befindet sich eine unbedeutende Quantität trüben blutig-katarrhalischen Exsudates. Der untere Lappen der linken latuge ist stark hyperämisch und mit Fibringerinnseln bedeckt. Das Exsudat besteht unter dem Mikroskop aus Reincultur des Bacillus pyocyaneus, Endothelzellen, rothen Blutzellen und einer geringen Beimischung von Eiterkörperchen. Auf Platten entwickelte sich nur Bacillıs pyocyaneus. Auf Durchschnitten, mit Methylenblau gefärbt, wurden die Bacillen im Biudegewebe der Milakapsel, in Peritonueum parietale und Diaphragma gefunden, aber nach einer 48 Stunden dauernden Färbung wurden sie in vielen Harnkanälchen (Fig. 3) und Malpighi'schen Körperchen in grosser Masse constatirt. Tod an Peritonitis fibrinoso-purulenta (incipiens).

Versuch 67. An 10. October wurde von einer 2tägigen Bacillus-pyocyaneus-Agarcultur I Platinöhse mit 5 ccm Wasser gut vermischt und davon $1 \mathrm{ccm}$ nach Mischung mit $6 \mathrm{ccm}$ Wasser in das Peritonäum eingespritzt, oder kurz gefasst: es wurde $\frac{1}{5}$ der Platinöhse Bacillus pyocyaneas eingespritzt. Das Kaninchen blieb am Leben.

Am 10. October ein Parallelversuch. - Das Kaninchen blieb ain Leben.

Aus den angeführten Experimenten ist ersichtlich, dass bei Einspritzungen einer ganzen Agarcultur von Bacill. pyocyaneus die Thiere im Laufe von 24-48 Stunden zu Grunde gehen, dabei wurde (bei 2 Kaninchen) Peritonitis fibrinoso-haemorrhagica constatirt. Nach Einspritzung unbedeutender Mengen dieser Bacillen - 2 Platinöhsen in $7 \mathrm{ccm}$ Wasser (zweiter Versuch) entsteht dieselbe Peritonitis und folgt der Tod nach 24-72 Stunden.

In dem einen, wie in dem anderen Falle besteht das Exsudat, unter dem Mikroskope betrachtet, hauptsächlich aus rothen Blutkügelchen und einer ungeheuren Quantität von Bacillus pyocyanens. In Deckglaspräparaten und in Agaraussaat wurde eine Reincultur dieser Bacillen erhalten, Nach Einspritzung aber (bei 2 Kaninchen) von $\frac{1}{5}$ der Platinöhse mit Bacill. pyocyan. in 6 ccm Wasser blieben die Thiere am Leben. Die Bacillen wurden auf Durchschnitten in den Lymphspalten des Centrum tendineum des Diaphragma, des Peritonaeum parietale, in den Bindegewebsspalten desselben, der Kapsel der Milz und Leber, ebenso auch in grossen Massen in den Harnkanälchen (Fig. 3) und Malpighischen Körperchen gefunden. 
In der Mehrzahl dieser Versuche bleibt der Charakter der Peritonitis ein fibrinös-hämorrhagischer, in Folge des raschen Todes unserer Versuchsthiere im Laufe von 20-24 Stunden, 1. h. im Laufe eines solchen Zeitraumes, in welchem der eitrige Charakter des Prozesses noch nicht zur vollen Reife kommen konnte. Als aber eines unserer Versuchsthiere (No. 62) 3 Tage überlebte, so zeigten sich bei ihm schon Symptome einer beginnenden Eiterung in der Form eines trüben (katarrhalischen) Exsudates mit Eiterelementen gemischt. Dieser Versuch ist äusserst lehrreich. Er zeigt den typischen Charakter der Einwirkung, welchen der Bacillus pyocyaneus auf das Gewebe ausübt, und bestätigt unsere angeführten Resultate, dass zur Erscheinung der Eiterung mehr Zeit nothwendig ist, als zu der der hämorrhagischen Entzündung, oder anders gefasst: je länger das Thier lebt, desto deutlicher tritt der eitrige Charakter des Prozesses zu Tage.

Auf Grund dieser Reihe von Versuchen ist man gezwungen, zu folgenden Schlüssen zu kommen: 1) Der Bacillus pyocyaneus ist pathogen. 2) Er vermehrt sich in den Geweben und in den Organen. 3) Seine Einspritzung in das Peritonäum ruft in kleinen Quantitäten acute tödtliche Peritonitis mit fibrinöshämorrhagischem Charakter hervor, oder bei länger dauerndem Leben der Versuchsthiere eine solche mit eiterigem Charakter des Exsudates. 4) Nach dem Charakter seiner Virulenz gehört er in die Gruppe der pyogenen Mikroben. 5) Pyogene Mikroben wie der Staphylococcus aureus, mit starker Virulenz, und ähnlich der Bacillus pyocyaneus, können die Ursachen der acuten eitrigen Peritonitis sein; wenn daher der Charakter der Virulenz bei der Einwirkung der pyogenen Gruppe der Mikroben unveränderlich bleibt, so werden auch diese Mikroben für den Organismus dieselbe Bedeutung haben. Kurz gefasst: Die Ursache der acuten eitrigen Peritonitis sind pyogene Mikroben und unter ihnen besonders und hauptsächlich der Staphylococeus aureus.

Die erwähnten Versuche mit Bac. pyoc. bestätigen die Versuche des Dr. Ledderhose in Hinsicht der pathogenen Eigenschaften dieses Bacillus, wie er es im September des Jahres 1887 auf der Naturforscher- und Aerzte-Versammlung za Wiesbaden 


\section{1}

vortrug, was mir damals durch Herrn Prof. Rasenbach mündlich mitgetheilt wurde.

Durch oben beschriebene Versuche sind also für die Frage nach der Aetiologie der acuten Peritonitis durch Infection oder Eintreten chemischer Substanzen von aussen, d. h. ob auf dem Wege von Verwundungen durch Stich oder Schnitt, durch operatives Oeffnen der Bauchhöhle nach Eiterung ihrer Wunde, Organe, wie der Gebärmutter, Harnblase und Nieren u. s. w., Gesichtspunkte gewonnen. Im Peritonäum befindet sich ein grosses Reservoir mit Infectionskeimen, - der Darmkanal. Im Darmsafte sind immer viele und sehr verschiedene Mikroben. Die klinische Erfahrung lehrt uns, dass Darmsaft im Peritonäum fast immer eine schwere und nicht selten eine tödtliche Peritonitis nach sich zieht. Den Durchbruch typhöser und tuberculöser Geschwüre und das Eindringen der Darmcontenta in das Peritonäum wird von acuter Peritonitis gefolgt. Der rasche Tod nach Wunden, Ruptur, Riss, Nekrose der Darmwände bei den verschiedenen Arten der Einkleminung erfolgt ebenfalls durch acute Peritonitis. Die Aufklärung der Rolle, welche der Darmsaft in der Aetiologie der Peritonitis nach Perforationen spielt, ist deshalb ausserordentlich wichtig.

Was für eine Noxe ist es, welche den Beginn der perforativen Peritonitis anregt? Besteht sie aus chemischen Stoffen des Darmsaftes, aus Fermenten oder aus darin enthaltenen Mikroben? Wenn aus letzteren, dann aus welchen? Erregen endlich Mikroben Peritonitis acuta, allein für sich oder möglicher Weise verbunden in Compositionen? Dies sind Fragen, welche dringend einer Antwort harren und welche in der Wissenschaft noch gar nicht gelöst sind. Es wird jedem einleuchten, dass ihre Lösung für theoretisches und klinisches Wissen von Wichtigkeit ist.

Diese Betrachtungen führten uns deshalb zu den folgenden Versuchen mit Darmsaft, welche sich beziehen auf die Rolle, welche letzterer in der Aetiologie der Peritonitis spielt.

Frischer Saft aus dem Dünndarme (vom Duodenum bis zum Processus vermiformis) eines frisch getödteten Kaninchens wurde unter Beobachtung bakteriologischer Vorsichtsmaassregeln 
in drei Theile getheilt, von welchen der erste 'Theil einigen Kaninchen sogleich za einer Spritze voll injicirt wurde - unfiltrirt; der zweite Theil nach Filtriren ebenfalls einigen zu $2 \frac{1}{2}$ bis $3 \frac{1}{2}$ Spritzen voll, der dritte Theil nach 8 tägigem Sterilisiren nach Tyndal wurde zu einer Spritze voll injicirt.

A. Unfiltrirter Darmsaft.

Versuch 36. Am 27. September wurde eine Spritze voll unfiltrirten Darmsaftes eingesprit $\%$. Tod nach 24 Stunden. Section: Allgemein ausgebreitete Peritonitis mit reicher Menge von Fibrinflocken, Injection und Hämorrhagien auf und in dem Peritonäum. Die Fäcalmassen sind üher verschiedene Theile des Peritonäum zerstreut und in frischem fibrinösenn Exsudate eingebettet. Im Peritonäalraume ein trübes (katarrhalisches?) Exsudat, welches unter dem Mikroskope hauptsächlich aus Eiterelementen, oft mit Mikrokokken gefüllt, und einer Menge kurzer Bacillen besteht. Auf Platten entwickelten sich dieselben eigenartigen kurzen Bacillen. Die letzteren wurden auf Durchschnitten auch in den Lympbspalten des Centrum tendineum gefunden.

Versuch 37. Am 27. September Parallelversuch mit demselben Resultate.

Versuch 42. Am 30. September wurde eine Spritze nnfiltrirten Darmsaftes eines eben getödteten Kaninchens eingespritzt. Tod nach 24 Stunden. Section: Im Peritonäum Hyperämie; die eingespritzten Stückchen Fäcalmassen sind in dünne fibrinöse Häutchen eingebüllt. Die letzteren bedecken auch die Milz und einen grossen Theil der Leber. Auf Deckgläschen und in Nährflüssigkeit wurden die oben erwähnten kurzen Bacillen constatirt.

Versuch 43. Am 30. September Parallelversuch. Tod nach 48 Stunden. Reichliche Mengen fibrinüser Häutchen, welche das Peritonäum an verschiedenen Stellen bedecken. Am Omentum Eiterheerde. Unter dem Mikroskope in Exsudate viele kurze Bacillen, welche sich auch auf Agarplatten in Form reichlich sich ausbreitender weisslicher Colonien entwickelten. Auf Durchschnitten aus dem Diaphragma zeigten sich die erwäbnten kurzen Bacillen in den Lymphspalten derselben.

\section{B. Frischer filtrirter Darmsaft.}

Versuch 37. Am 27. September. $7 \mathrm{ccm}$ (1 Spritze) durch mehrere Lagen Filtrirpapier durehgelassenen Darmsaftes wurden einem Kaninchen eingespritzt. Bei der mikroskopischen Untersuchung sieht man in ihm einige wenige Mikroben des Darmkanals in Form a) von schlanken, b) von soliden Bacillen, c) kurze Bakterien, d) Kokken und e) Pflanzenzellen. 28. September: Das Kaninchen ist traurig, apathisch. Am 30. September munter, gesund.

Versuch 38. Am 27. September. Parallelversuch zu dem vorigen. 31 Spritzen filtrirten Darmsaftes eingespritzt. Das Filtrat ist trübe, von alkalischer Reaction. Dasselbe mikroskopische Ergebriss, wie in Versuch 37. Das Kaninchen blieb am Leben. 
Versuch 44 und 45 . Am 30 . September 3 und $2 \frac{1}{2}$ Spritzen injicirt nit demselben Resultate.

C. Versuche mit frischem, nicht filtrirtem, aber nach Tyndal sterilisirtem Darmsafte.

Die dritte Portion frischen Darmsaftes wurde nach Tyndal der unterbrochenen Sterilisation unterworfen während einiger Tage, je eine Stunde täglich bei $58^{\circ} \mathrm{C}$. Es zeigte sich, dass der Darmsaft durch diese Methode sehr schwer zu sterilisiren ist. Nach 4tägiger Sterilisation entwickelten sich in der Probeaussaat auf Agar und Fleischpepton-Gelatine Mikroben (Streptococci). Deshalb wurde das Sterilisiren noch 2 Tage fortgesetzt. Indem ich annahm, dass nach 6 Tagen der Saft sterilisirt sei, spritzte ich ihn zweien Kaninchen ein und säete zu gleicher Zeit von dem Safte auf Nährsubstrat; beide Thiere starben aber, eines am anlderen Tage, das zweite nach 2 Wochen, und in der vorerwähnten Aussaat aus dem Safte entwickelten sich ebenso, wie aus dom Exsudate des Peritonäum, nach dem Tode Streptokokken bei dem ersten und kurze Bacillen mit abgerundeten Enden bei dem zweiten. Es zeigte sich auf diese Weise, dass selbst eine 6tägige Sterilisation ungenügend ist, den Saft keimlos zu erhalten, deshalb wurde der übrige Theil diẻses Saftes einer weiteren 2 tägigen Sterilisation während 2 Stunden täglich bei $58^{\circ} \mathrm{C}$. unterzogen. Danach, also nach 8 Tagen, wurden Impfungen gemacht auf Agar-Agar. Auf denselben entwickelten sich gar keine Mikroben. Dann erst wurden von diesem Safte $7 \mathrm{ccm}$ einem Kaninchen oingespritzt. Es blieb am Leben.

Diese 3 letzteren Versuche wurden angeführt theils wegen ihres besonderen Interesses, wie die 2 ersten, der letzte aber als Hauptcontrolversuch.

Versucb 50. Am j. October wurden nach 6tägigem Sterilisiren eine Spritze Saftes (von welchern früher in den Versuchen $42-45$ benutzt wurde) eingespritzt. Tod am 6. October. Section gleich nach dem Tode. Ejbrinöshämorrbagische Peritonitis. Milz und Leber mit vielen dicken Gerinnseln bedeckt. Auf den Gedärmen - dünne Häutchen - wie angehaucht und stellenweise Extravasate und Ecchymosen. Im Peritonäum keine grosse, aber im Pleuraraum eine berleutende Menge blutigen Exsudates. Das Exsudat besteht hauptsächlich aus rothen und wenigen weissen Blutkörperchen, soliden Bacillen und Streptokokken. Auf Agar erscheinen Streptokokken. 
Versuch 51. Am 5. October Parallelversuch zu dem vorbergehenden. $1 \frac{1}{2}$ Spritzen Saft wurden eingespritzt. Tod am 19. October. Section: Eitrigfibrinöse Peritonitis. Allenthalben Verwacbsungen der Gedärme untereinander und mit der vorderen Bauchwandung. Zwischen den Darmschlingen sind hier und da harte Klämpchen der eingespritzten Darmcontenta zu sehen, umgeben von mit Eiter durchsetzten Fibringerinmseln. Diese Klümpchen hängen stellenweise den Gedärmen an, wie Appendices epiploicae. In Deckglaspräparaten eine Masse Eiterkörperchen, und zuweilen wird der schon mehrmals erwähnte kurze eigenartige Bacilus mit seinen abgerundeten kinden gesehen.

Controlversuch 59. Am 8 . October eine Spritze eines wäbrend 8 Tagen sterilisirten Saftes eingespritzt. Das Kaninchen blieb munter und gesund.

Aus oben erwähnten drei Reihen von Versuchen mit Darmsaft sehen wir, dass nur der unfiltrirte auf Thiere absolut tödtlich wirkt, da alle 4 Thiere dieser Reihe an acuter Peritonitis zu Grunde gingen. Wir können also anf Grund dieser Versuche den directen Schluss ziehen, dass als tödtlicher Agent der Perforativeritonitis der Darmsaft erscheint. Aber welcher seiner Bestandtheile ist giftig? Die Mikroben oder die chemischen Substanzen, allein oder zusammen, in Gemeinschaft?

Wir sehen, dass durch Filtrirpapier durchgelassener Darmsaft den Thieren nicht giftig ist, "da alle 4 Kaninchen der zwejten Reihe - B - genasen, wenn auch in dem in sie eingespritzten frischen Filtrate zweifellos alle chemische Substanzen des Darminhaltes enthalten waren. Ebenso befanden sich diese Substanzen auch in dem während 8 Tagen sterilisirtem Darmsafte und dennoch blieb das Controlkaninchen der dritten Reihe C gleichfalls am Leben. Die chemischen Stoffe des Darm. saftes spielen also bei der Perforativperitonitis keine ätiologische Rolle.

Scheinbar sprechen freilich unsere Versuche mit filtrirtem Darmsafte gegen die Mikroben, da in dem Filtrate Mikroben waren und die Thiere dennoch am Leben blieben. Aber 1) es waren deren ausserordentlich wenig, oder - für den Skeptiker anders ausgedrückt - es waren in dem Filtrate ohne Zweifel bedentend weniger Mikroben, als im unfiltrirten Safte; 2) die Mikroben des unfiltrirten Saftes, welche in dem todten Nährmaterial, in den mit dem Darmsafte eingespritzten Klümpchen verblieben, befanden sich in günstigeren Verhältnissen für ihre 
Rahe und Vermehrung, als die Mikroben des flüssigen Filtrates, welche theils rasch durch die Stomata des Peritonäums aufgesogen, durch dieselben in den allgemeinen Kreislauf und die absondernden Organe gelangten, theils von den Phagocyten aufgezehrt wurden. Dass Minimaldosen Mikroben ohne Schaden von dem Organismus verdaut werden können, beweisen die oben crwähnten Versuche mit Staphylococcus aureus. Sogar für Mikroben, wie Staphylococcus aureus mit starker Virulenz, giebt es eine Grenze (bei Injectionen in das Peritonäum), über welche hinaus der Organismus mit einem bestimmten Minimum von Mikroben fertig wird, und es bedarf besonders günstiger Momente zur Hervorbringung ihrer Wirkung auf den Organismus. Wir werden später nochmals auf diesen wichtigen und interessanten Punkt zurückkehren.

Wenn daher als Ursache der Peritonitis nach Perforation die Mikroben des Darminhaltes anzusehen sind, so erscheint natürlich die wissenschaftlich zu erläuternde Frage: Welcho Mikroben des Darminhaltes verursachen die Perforativperitonitis? In den oben besprochenen Versuchen mit Darmsaft wurden bei den meisten Kaninchen im Peritonäalexsudate und auf der Peritonäalwand eigenartige kurze Bacillen mit abgerundeten Enden beobachtet. Die beständige Anwesenheit dieser Bacillen bei den letzten vier Kaninchen zog die Aufmerksamkeit auf sich.

Auf Deckgläschen wurden die Mikroben in Reincultur gefunden. Es genügte, mit der Platinöhse über die Serosa des Peritonäums zu fahren, um sie unter dem Mikroskope massenhaft zu sehen.

Die negativen Resultate in den Versuchen mit dem Filtrate des Darmsaftes, die Unschädlichkeit des sterilisirten Saftes und die beständige Anwesenheit oben genannter Bacillen im Exsudate bei tödtlicher Peritonitis regten dazu an, ihre Rolle and Bedeutung in der Peritonitis aufzuhellen. Deshalb wurden diese Bacillen zum besonderen Gegenstande eines eingehenden Studiums gemacht.

Es zeigte sich, dass in der Aussaat auf Agar-Agar und auf Plattencultur diese Bacillen sich bei einer Temperatur von $35^{\circ}$ C. schon nach 24 Stunden in reichlichen Colonien entwickeln, ähnlich den fetten glänzenden Tropfen von dickem Schmande. 
Diese Tropfen zeigten sich unter schwacher Vergrösserung gekörnt mit glatten Rändern; bei der Untersuchung in Immersion jedoch erschienen diese Mikrobencolonien ungefärbt als kurze unbewegliche Stäbchen mit abgerundeten Enden, zuweilen zu zwei vereint. Sie sind an den Rändern etwas dunkler (ungefärbt sind sie stärker lichtbrechend); junge Exemplare sind oval und kurz.

Nach einer Färbung von einer Dauer von 24 Stunden in wässriger Aufösung von Methylenblau färben sich die Enden dieser Bacillen intensiver, als ihre Mitteltheile (Fig. 4a).

Sie wachsen rasch in Agar-Agar. Die Cultur von 24 Stunden zeigt sich als ein üppiger, öliger, glänzender, grau-weisser Strich. Die Gelatine wird durch sie nicht verflüssigt. Sie wachsen auf derselben bei gewöhnlicher Temperatur, wenn auch langsamer, als auf Agar; aber im Ganzen doch auch rasch so, dass in zwei Tagen die Striche sich zur Nagelform mit Köpfchen von grau-weisser Farbe entwickeln. Nach 5 Tagen erscheint das Köpfchen wie kleinkörnig und sammetartig; sein Rand ist nicht glatt und verbreitert sich strahlenförmig der Peripherie entlang, während sich im Centrum die Mikroben dichter entwickeln.

In der Längsrichtung des Impfstiches befindet sich in der Gelatine auf dem Einstichcentrum ein knopfförmiger Auswuchs und zuweilen am 4. bis 5. Tage werden Gasbläschen sichtbar, welche unter spitzem Winkel das Centrum der Cultur durchschneiden. Im Anfange erscheinen diese Bläschen unter der Cultur, nach und nach, etagenweise nehmen sie das ganze Centrum der Cultur ein bis zur gleichen Oberfläche der Fleisch-PeptonGelatine im Reagenzgläschen.

Im hängenden Tropfen, in der feuchten Kammer sind die Bacillen unbeweglich. Nach 24 Stunden wachsen sie hier zu langen Fäden aus, zu Ketten, deren Glieder schwach zusammenhalten und bei unzarter technischer Behandlung auseinanderfallen (Fig. 4a). Nach 24 Stunden zeigen sich in einzelnen Fäden kleine, Sporen ähnliche Körnchen (Fig. 4b). In drei- und fünftägigen Culturen sieht mau wièder nur kurze Bacillen und eine Masse von Sporen; dabei ordnen sich die Bacillen zu Fäden an, reihenweise ihrer Längsaxe parallel. 
Die biologischen Eigenschaften erwähnter Bacillen unterscheiden sie also deutlich von den übrigen für Thiere pathogenen Mikroben. Bei dem ersten Anblicke erinnern sie etwas an die Bacillen der Kaninchensepticämie Koch's, aber sie unterscheiden sich von diesen durch ihre Grösse, ihren raschen Wuchs auf Agar und Fleisch-Pepton-Gelatine, häufige Gasentwickelung in der Gelatine entlang der Längsaxe des Impfstiches und durch Sporenentwickelung.

Die durch Plattenzüchtung in Agar erhaltenen Reinculturen wurden damn in das P'eritonäum von 9 Kaninchen und 2 Hunden eingespritzt. Ich führe hier einige typische Versuche an.

Versuch 57. Am 6. October wurde eine 4tägige Agarcultur von Bacillus peritonitidis in einer Spritze Wasser eingespritzt. Tod in der Nacht am 7. October. Section. Alle Gedärme sind mit einer charakteristischen, fadenziohenden, schleimigen, weisslichen Masse überkleidet und stellenweise mit reichlichen punktförmigen Hämorrhagien besïet. In den tieferen Theilen des Peritonäum befindet sich eine unbedeutende Menge trüben Exsudates. Die Organe sind welk; die Milz vergrössert. Das Herz mit geronnenem Blute gefüllt. Lungen durehgängig, die unteren Lappen hyperäwisch. Auf Deckglaspräparaten (Material von der l)armserosa) eine Masse Bacillen. Oben erwähnte schleimige Masse besteht hauptsächlich aus Bacillen mit einer geringen Beimengung von weissen Blutkörperchen. Durch Plattenverfahren entwickelten sich dieselben Mikroben. Tod an Peritonitis haemorrhagica mycotica.

Versuch 58. Am 6. October Parallelversuch zu dem vorigen mit einer Cultur von gleicher Reife. Des Morgens am 7. October Tod. Section einige Minuten nach dem Tode. Alle Gedärme, das Peritonäum parietale wie tnit Schleim, von einer fadenziehenden, schmutzig-weissen Masse äberzogen unter Beimengung von Fibrinflocken. Reichliche kleine Hämorrbagien über die ganze Tarmserosa. In den tieferen Theilen des Peritonäum eine geringe Menge trüben klebrigen Exsudates. Die Organe welk. Milz und Leber vergrössert, mit zarten Fibrinhäutchen bedeckt. In Deckglaspräparaten eine Masse von Bacillus peritonitidis. Das Exsudat auf den Gedärmen sowohl als auch im Peritonäalsacke besteht hauptsächlich aus genannten Mikroben, selten sind weisse Blutkügelchen.

In Impfungen anf Agar-Agar entwickelten sich diese Bacillen reichlich. Auf Durchschnitten von Leber und Nieren wurden keine Organismen entdeckt. In der Milz dagegen sind deren eine Masse und verbreiten sie sich von der Peripherie aus den Bindegewebsspalten der Milzkapsel und den Trabekeln entlang. In den oberflächlichen Milzzellen werden auch viele Bacillen gesehen. Im Centrum des Organes sind gar keine Bacillen. Peritonitis haemorrhagico-fibrinosa mycotica. 


\section{8}

Versuch 63. Am 8. October wurden 2 Platinöhsen von Bacillus pexitonitidis in einer Spritze Wasser injicirt. Tod am 11. October. Section. Starke Darmhyperimio. Viele Fibrinflocken auf Mil\% und Omentum. Vereinzelt hier und da kleine Petechien auf den Darme. Die schleinige Flüssigkeit, welche den Darm in geringer. Menge überzieht, ist trübe. Leber vergrössert, blass. Herz blass, mit Blutgerinnseln gefült. Nieren morsch, hyperämisch. I,ungen blass. Auf Deckgläschen - aus dem Exsudate - Bacillen, Peritonäalepithelien und viele Eiterkörperchen.

In Impfungen anf Agar-Agar wurden Reinculturen von Bacillus peritonitidis erhalten. Auf Durchschnitten wurden die Hikroben in den Lymphspalten des Centrum tendineum (Fig. 5) und im Bindegewebe der Lungen gefunden, die letzteren waren zugleich entzündet und stark mit Granulationsgewebe durchsetzt. In Nieren and Leber wurden keine Mikroben entdeckt. Peritonitis fibrinoso-purulenta (ineipiens).

Versuch 64. Am 8. October Parallelversuch dem vorigen. Am 9. 0ctober todt. Im Ganzen dieselben Erscbeinungen bei der Section.

Versuch 80. Am 17. October Parallelversuch zu Versuch 63. 8tägige Cultur. Am 18. October todt. Die Därme mit obenerwähnter schleimiger Flüssigkeit bedeckt. Hier und da kleine Flocken. In den tieferen Stellen des Peritonäum kein Exsudat. Die Organe hyperäwisch. Von der Serosa anf Deckglas genommen, zeigt eine bedeutende Nenge Eiterelemente, Epithelialzellen unci Bacillen. Starke Eiterinfiltration des Mesenteriums und zerstreute Colonien und Gruppen von Bacillen in ihm. Peritonitis fibrinoso-purulenta (incipiens).

Versuch 81. Am 17. October Parallelversuch zu dem vorigen. Tod am 19. October. Im Peritonäalraum eine ungeheure Menge flüssigen, eitrigen trüben Exsudates. Starke Hyperämie der Darmserosa mit Fibrin- und Eiterflocken bedeckt. Milz vergrössert. In der Pleura unbedeutende Henge durehsichtigen serösen Exsudates. Auf Deckglaspräparaten zeigt im Exsudate Bacillen und eine Masse von Eiterelementen. Das Mesenterium ist mit Eiterelementen infiltrirt. In seinen Lymphspalten viele Bacillen. Auf Agar Bacillus peritonitidis in Reincultur. Tod an Peritonitis purulenta.

Versuch 65. Am 10. October. Eine Platinöhse Mikroben wurde mit $5 \mathrm{ccm}$ sterilisirten Wassers vermischt. Davon wurde $1 \mathrm{ccm}$ der Mischung mit $7 \mathrm{ccm}$ Wasser in das Peritonäum gespritzt. Tod am 14. October. Im Peritonäum trübe, schleimige, klebrige Flüssigkeit. Hier und da Fibrinund Eiterflocken. Hyperämie der Serosa. Niereninfarct. Unter dem Mikroskope im Exsudate Bacillen und viele Eiterelemente. In Impfungen auf Agar-Agar entwickelten sich die eingespritzten Bacillen.

Versuch 66. Parallelversuch 74 dem vorigen. Das Kaninchen blieb am Leben.

Versuch 33. Am 17. October wurde einem grossen schwarzen Pudel eine 7tägige Agarcultur von Bacillus peritonitidis in einer Spritze Wasser 
eingespritzt. Tod am 18. Octoter. Auf Darm, Netz, Peritonaeum parietale sehr viele Extravasate. Eine bedeutende Menge blutigen Exsudates im Peritonäum. Extravasate in den unteren Lappen der Lungen und anf dem Diaphragma. Milz vergrössert. Tod an Peritonitis haemorrhagica. Das Exsudat besteht unter den Mikroskope hauptsächlich aus rothen Blutkörperchen, aber stellenweise in Form dichter Colonien mit einer bedeutenden Menge von weissen gemischt (Beginn der Eiterung?). In Agarzüchtung dieselben Bacillen. Auf Durchschnitten wurden sie im Peritonaeum parietale, Centrum tendineum, in grosser Menge in den Nieren - in ihrem Bindegewebe und in den Lumina der Harnkanälchen (Fig. 6) - , in den Blutgefässen und dem Gewebe der Lungen und der Leber gefunden.

Versuch 84. Am 17. October. Parallelversuch zu dem vorigen. Eine kleine schwarze Hündin, welche am anderen Tage nach der Injection stark leidet, nicht aufsteht und traurig ist, stebt am dritten Tage wankend, traurig und frisst nichts, erholte sich aber am 4. Tage und blieb am Leben.

Aus dieser Reihe von Versuchen mit Bacillus peritonitidis ex intestinis cuniculi sehen wir also, dass nach Einspritzung grosser Quantitäten Kaninchen (2) in 20-24 Stundeu an allgemeiner hämorrhagischer Peritonitis starben, unter den oben beschriebenen eigenartigen Erscheinungen am Peritonäum. Nach Einspritzung kleiner Quantitäten des Bacillus peritonitidis (2 Platinöhsen, 5 Versuche) starben die Kaninchen oft an Peritonitis im Laufe von 24-72 Stunden; dabei wird bei den rasch Absterbenden am ersten Tage Peritonitis fibrinosa-purulenta (incipiens), bei länger Lebenden (3-14 Tagen) Peritonitis purulenta constatirt. Nach Einspritzung $\frac{1}{5}$ Platinöhse Mikroben starben von 2 Kaninchen eines an Peritonitis fibrinosa-purulenta, das andere genas. Nach Einspritang einer Agarcultur starben von 2 Hunden einer nach 24 Stunden an Peritonitis haemorrhagica purulenta (incipiens), der andere überlebte die. Infection, obgleich er einige Tage schwer krank war.

Der Bacillus peritonitidis steht also ohne Zweifel in ätiologischer Beziehung zur acuten Peritonitis unserer Thiere, welche durch Eintritt von Darminhalt in das Peritonäum entsteht. Die Mikroben des Darminhaltes sind folglich im Allgemeinen die Erreger der Perforativperitonitis.

Der Charakter der acuten Peritonitis, an welcher die Thiere nach Einspritzung mit'Bacillus peritonitidis zu Grunde gehen, unterscheidet sich etwas von dem gewöhnlichen pathologisch-anatomischen Bilde. Nicht selten ist auf dem Peritonäum gar kein 
deutlich ausgeprägtes Bild zu bemerken, selbst nicht einmal eine starke Hyperämie. Indessen besteht das Exsudat in solchen Fällen ausschliesslich aus einer ungeheuren Masse der eingespritzten Mikroben. Sie befinden sich haufenweise auf der Darmserosa. Die fadenziehende gallertartige Exsudatflüssigkeit stellt gewissermaassen eine ungeheure Bakteriencolonie dar (nicht selten Zooglöamasse). Man hat nur von der Darmserosa mit der - Platinöhse zu schöpfen, so findet man auf dem Deckgläschen reichlich Mikroben in Reincultur. Wir haben dann angenscheinlich in solchen Fällen Peritonitis mycotica vor uns. In anderen Fällen bemerkt man im Gegentheile eine Reibe von Hämorrhagien im Peritonäum, von geringen Extravasaten angefangen, bis zu breiten Ecchymosen und grossen Mengen hä1norrhagischen Exsudates. Es ist bemerkenswerth, dass unter dem Mikroskope in solchen Fällen schon und, nach rasch erfolgtem Tode, eine mehr oder weniger bedeutende Beimengung eiteriger Elemente zum Exsudate beobachtet wird. Je länger das Thier lebt und bei geringerer Qualität der eingespritzten Mikrobenmassen, vermehrt sich die Eiterbeimengung des Exsudates. Das letztere wird immer trüber und nimmt den Charakter des sogenannten katarrhalischen Exsudates an, oder richtiger gesagt, der Peritonitis purulenta incipiens. In der Folge nimmt das Exsudat an Menge zu und erhält zuletzt, bei 3-4tägigem Leben der Thiere einen deutlichen eiterigen Charakter. Diese Verschiedenheit des Charakters der Peritonitis, welche von der Lebensdauer des Thieres, und der geringen Menge der eingespritzten Mikroben abhängt, ist sehr charakteristisch und wiederholt sich in den oben angeführten Reihen von Versuchen mit derselben unveränderlichen Beständigkeit, wie in den vorhergehenden Versuchsreihen mit Staphylococcus aureus und Bacillns pyocyaneus. Endlich giebt es für Bacillus peritonitidis, ebenso wie für Staph. aur. und Bacill. pyoc., ein Minimum von Mikroben, welches vom Organismus ertragen wird. Dieses Minimum ist augenscheinlich nicht gleich für verschiedene Mikroben und verschiedene Thiere, und je giftiger oder virulenter der Mikrob, desto kleiner ist natürlich das virulente Minimum. So sahen wir, dass es am kleinsten für den Staphylococcus aureus ist und sich reducirt bis zur unbedeutendsten Quantität, möglicher Weise bis auf 
einige Mikroben; für den Bacillus peritonitidis - ist es grösser als für den Staphyl. aureus, nehmlich etwas kleiner wie $\frac{1}{5}$ Platinöhse (von Zweien gesundete Eines); für den Bacillus pyocyaneus beträgt er $\frac{1}{5}$ Platinöhse (beide Kaninchen genasen).

In dem Vorhergehenden sind Versuche über die Rolle und die Bedcutung der chemischen Substanzen, der Verdauungsfermente, der chemischen Stoffwechselproducte der Mikroben, der nicht pathogenen und der pathogenen Mikroben in der Aetiologie der Peritonitis mitgetheilt; ebenso ist auf die Rolle und Bedeutung des unfiltrirten, filtrirten und sterilisirten Darmsaftes hingewiesen worden. In den Bacillen des Dünndarmsaftes ist das Infectionsagens die Ursache, welche in unseren Versuchen die acute Perforationsperitonitis erregte, aufgefunden.

Wir haben noch eine ganze Reihe wesentlicher Fragen zur Lösung vor uns.

Jede Infection, indem sie in den lebenden Organismus eindringt, begegnet dort gewissen günstigen oder ungünstigen Bedingungen oder besser Einflüssen, mit welchen sie verschiedene Combinationen eingeht und in unbeständigem Kampfe sich befindet. Die Phasen und die Wandlungen des Kampfes bilden eines der wichtigsten und interessantesten Capitel der Pathologie der nächsten Zukunft.

In den mitgetheilten Versuchen wurden schon einige dieser Einflüsse auf die Infection, welche von dem Organismus ausgehen, theilweise bemerkt und auf einige Bedingungen hingewiesen, unter welchen die Infection in das Peritonäum eintritt. Die bedeutende Resorptionsfähigkeit des Peritonäum bildet augenscheinlich eine ungünstige Bedingung für das in das Peritonäum eingedrungene Minimum von Mikroben. Wenn diese Mikroben in die Flüssigkeit des gesunden Peritonäum gerathen, so können sie rasch von ihm aufgesogen und durch die Ausscheidungsorgane aus dem Organismus fortgeschafft werden. Wenn sie jedoch, in harten Partikelchen von todtem Nährmaterial oder von Verbandstoffen eingehüllt, indem sie sich mit Blutklümpchen oder Fibrin umgeben, in das Peritonäum eintreten, oder wenn sie einen Riss oder eine Spalte im Peritonäum finden, wo Mikroben sich festsetzen, halten und vermehren können, - so begegnen sie im Peritonäum in den ersten Lebensstunden güustigen 
Bedingungen für ihre zerstörenden Lebensäusserungen. So war es in unseren Versuchen mit unfiltrirtem Darmsafte, wo der Bacillus peritonitidis, mit harten Partikelchen eingespritzt, bei allen Thieren eine tödtliche acute Peritonitis bedingte und dieselben Bacillen, in geringeren Quantitäten und ohne diese harten Klïmpchen, in den Versuchen mit filtrirtem Darmsafte, im Gegentheile keine Peritonitis hervorriefen, die Thiere vielmehr genasen. Man wird möglicher Weise sagen, dass die letzten Versuche gegen die Mikroben sprechen; es wird aber viel richtiger sein, anzunehmen, dass das Filtrat des Darmsaftes äusserst wenige Mikroben enthält, während deren in den harten Klümpchen des Darmsaftes viele beherbergt werden und diese Klümpchen den Mikroben als Boden für die weitere Entwickelung dienen. Wir haben oben ferner darauf hingewiesen, dass die löslichen chemischen Fermente des Darmsaftes keine atiologische Hauptrolle in der Peritonitis spielen, da in unseren Versuchen der filtrirte Darmsaft nicht giftig auf die Thiere wirkt. Ausserdem ertragen die Thiere ohne Schaden ein gewisses Mininum von Mikroben. Eine andere Frage ist es, ob sie jenes Minimum in Verbindung mit unbedeutenden Mengen chemischer Reizerreger der Gewebe, Fermente u. s. w. ertragen d. h. in Gegenwart eines leichten acuten irritirenden (entzündlichen?) Gewebszustandes?

Den Einfluss dieser für das Leben der Mikroben im Peritonäum günstiger Momente $z u$ verfolgen, bildet unsere letzte Aufgabe. Es versteht sich von selbst, dass solche Momente sehr verschieden sein können. Sie alle experimentell zu verfolgen, übersteigt die Kräfte eines einzelnen Menschen, aber wir sind im Stande, uns mit den hervorragendsten Momenten im Leben und in der Praxis zu beschäftigen - dies wird unsere directe Aufgabe sein. Die letzte Reihe unserer Versuche bezieht sich deshalb auf die ätiologische Rolle minimaler, für die Thiere unschädlicher Quantitäten von Mikroben bei der Peritonitis in Gegenwart einiger günstigen für sie, chemischer und mechanischer Lebens- und Entwickelungsbedingungen. In der Absicht, den Einfluss von Mikroben auf das Peritonäum in Gegenwart von indifferentem Nährstoffe zu beobachten, wurde Staphylococcus aureus in minimalen, für Kaninchen unschädlichen Quan- 
titäten (s. oben) in Verbindung mit Agar-Agar, welches nahe dem Erkalten war, eingespritzt. Es wurden in dieser Reihe 8 Experimente ausgeführt. Leider zeigten sich vier vou ihneu, bei welehen, ehe wir die Virulenz unserer Mikroben kannten, zu grosse Quantitäten gespritzt warden, überflüssig. Nachdem durch Experimente festgestellt worden war, dass Agar-Agar allein den Thieren unschädlich ist, wurde ferner die äusserst interessante Thatsache gefunden, dass im Gegentheile für die Thiere minimale unschädliche Mengen von Staphylococcus aureus in Verbindung mit Agar nach 24-36 Stunden den Tod der Thiere an Peritonitis acuta fibrinosa haemorrhagica purulenta hervorruft.

Versuch 73. Am 11. October wurde 1 Spritze mit sterilisirtem Eleischpepton-Agar-Agar eingespritzt. Das Kaninchen blieb munter und am Leben.

Versuch 98. Am 26. October wurden $7 \mathrm{ccm}$ Agar-Agar mit. 2 Platinöhsen von Staph. aur., aus einem Filtrate von einer Platinöhse in 5 cem Wasser genommen, eingespritzt. Tod am 1. November. Typische eitrige Peritonitis mit einer bedeutenden Ansammlung von Eiter zwischen den Gedärmen und dem Netze, der Leber und dem Diaphragma. Die Getürme an vielen Stellen mit der vorderen Bauchwand verklebt. Milz vergrössert. Nieren vergrössert (Nepbritis parenchymatosa). Auf Deckgläschen Staphyl, aureus inmitten einer Masse von Eiterelementen. In Culturen entwickelten sich dieselben Kokken.

Versuch 99. Am 26. October Parallelversuch zu dem vorigen. Tod am 28. October. Starke Hyperämie und Hämorrhagie der Darmserosa. Trübes blutiges Exsudat in bedeutender Quantität im Peritonäalraume. Milz vergrössert. Starke Hyperämie in den Nieren und der Leber. Eine geringe Quantität serösen Fixsudates in der Pleura. Zerstrent im Peritonäum Partikelchen des eingespritzten Agar-Agar von der Grösse eines Hirsekornes bis zu der einer Erbse, durchdrungen und umgeben von Fibrin. Unter dem Mikroskope zeigt das Exsudat Staphylococei anrei mit einer bedentenden Beimischung von Eiterelementen. In Agarcultur Staphyl. aur,

Versuch 100. Am 26. October Parallelversuch zu dem vorigen. Tod am 28. October. Starke Hyperämie und kleine hämorrhagische Heerde in der Serosa. Bedeutende Quantität träben blutigen Exsudates im Peritonäum; Agarstückchen umgeben von Fibrinbäutchen. Milz stark vergrössert, von kleinen Fibrinflocken umgeben. Durchsichtiges seröses Exsudat in der Pleura. Auf Deckgläschen Staphylokokken in Reincultur. Die letzteren sitzen in Haufen und in reichlichen Colonien in den eingespritzten Agarpartikelehen, dieselben durehwaehsend. In Uebrigen derselbe Befund, wie im die Section des Versuchs 99 ergeben hat. 


\section{4}

Versuch 101. Am 26. Oetober Parallelversuch zu dem vorigen. Tod am 28. Octobes. Dieselben Ergebnisse bei der Section, der mikroskopische und bakteriologische Befund, wie in Versuch 100.

Aus dem Vorhergehenden ist deutlich zu sehen, dass die dichten Agarklümpchen, $d$. h. das indifferente Nährmaterial, indem sie die Mikroben beherbergen und bei sich behalten, zu dem ruhigen Gedeihen derselben und folglich zur Entscheidung der Peritonitis beitragen. Folglich können auch Blutpartikelchen, Stückchen von Fibrin, von zerknetetem oder unterbundenem Gewebe bei Laparotomien, Fremdkörper u. s. f, wenn sie, durchdrungen von Mikroben, im Peritonäum verbleiben, bei dem Menschen zum Auftreten einer acuten Peritonitis Veranlassung geben.

Zur Erklärung des Einflusses minimaler unschädlicher Quantitäten von Nikroben auf das Peritonäum bei Gegenwart chemischer Substanzen und Fermente ${ }^{1}$ ), welche eine leichte Entzündung des Peritonäums hervorrufen, wurden endlich folgende letzte Versuche ausgeführt:

A. Staphylococeus aureus +01 . crotonis.

Versuch 92. Am 22. October wurde in $7 \mathrm{~cm}$ Wasser $\frac{1}{10}$ Tropfen 01 . crotonis mit folgender Quantität von Mikroben eingespritzt: eine Platinöhse mit Staph. aur., vermischt mit $5 \mathrm{ccm}$ Wasser, wurde filtrirt. Von dem Filtrate wurden 2 Platinöhsen der obigen Quantität 01 c crot. hinzugefügt. Tod am 23. October nach 24 Stunden. Hyperämie des Peritonäum, Fibrinflocken auf der Serosa des Dickdarmes und vorderen Wand des Bauches. Nilz vergrössert. Grosse Mengen trüben blutigen Exsudates in Peritonäalranme und durcbsichtigen klaren Exsudates im Pleuraraume. Auf dem Deckglase besteht das Exsudat aus Eiterkörperchen und vielen Staphylokokken in Reincultur. Auf Agar-Agar entwickelten sich Reinculturen des Staphyl. aureus. Auf Durchschnitten wurde derselbe im Centrum tendineum, im Peritonaeum parietale und in der Milz gefunden. Tod an Peritonitis fibrinosopurulenta incipiens.

1) In dieser Reihe von Versuchen mit Staphyl, aureus + 01. crotonis und Trypsin wurde eine Anzabl von Versuchen, in Folge der Angaben von Grawitz, mit grossen Quantitaten von Staphyl. aureus, theils mit Ol. crot., theils mit Trypsin, welche schon ohne diese chemischen Substanzen heftig anf das Peritonäum wirken, ausgeführt, bevor wir das für das Peritonäum unschädliche Ninimum bestimmt hatten, Versuche, welche als überflüssig bezeichnet werden können. Sie weyden theilweise in der Tabelle angefübrt werden. 
Versuch 93. Am 22. October Parallelversueh zu dem vorigen. Nach $2 \dot{4}$ Stunden todt. Starke Hyperämie des Darmes, Fibrinflocken auf seiner Serosa. Eine bedeutende Quantität trüben (sogenannten katarrhalischen) Exsudates im Peritonäum. Milz deutlich vergrössert und mit Fibrinflocken bedeckt. In der Pleura bedeutende Quantität serösen Exsudates. Unter dem Mikroskope sieht man im Exsudate Eiterkörperchen und Staphylococeus aureus in Reincultur. Derselbe èrscheint auch in Aussaat anf Agar-Agar. Auf Durchschnitten wurde dieses Mikrob gefunden in der Kapsel, den Trabekeln und der angrenzenden Pulpa der Milz (in den Centraltheilen der Pulpa wurdeu sie nicht gefunden), sowie im Centrum tendineum diaphragmatis. Tod an Peritonitis fibrino-purulenta incipiens.

Versuch 94. Am 24. October wurde einem sehr grossen Kaninchen $\frac{19}{20}$ Tropfen 0l. crotonis mit derselben Quantität von Staphylokokken, wie in Versuch 92 eingespritzt. Tod nach 5 Tagen am 29. October. Intensive eiterige Peritonitis. Der ganze Peritonäalraum ist mit grossen Eiterflocken besät, welche die Gedärme unter einander und mit der vorderen Bauchwand verkleben. Hier und da befinden sich auch Eiterheerde an der vorderen Bauchwand, dem Netze; der Leber und Milz, welche stark vergrössert ist. Die Resultate der bakteriologischen und mikroskopischen Untẹsucbungen sind dieselben, wie im vorigen Versuche.

Versuch 95. Am 24. October Parallelversuch zu dem vorigen. Tod am 25. October. Leichte Hyperämie des Peritonäum. Zwischen Darmschlingen und den tieferen Stellen des Peritonäum eine charakteristische, schleimige, trübe Flüssiglseit in unbedeutender Quantität. Milz mässig vergrössert. Keine besonderen Veränderungen in den übrigen Organen. Die trübe Flüssigkeit besteht unter dem Mikroskope ausschliesslich aus Staphyl. aur., mit seltener Beimischung hier und da von weissen Blut- (bezw. Eiter-)körperchen. Auf Agar Reincultur von Staphyl. aur. Tod an Peritonitis mycotica.

\section{B. Staphylococcus aureus + Trypsin.}

Versuch 90. Am 22. October wurde $\frac{1}{20} \mathrm{~g}$ Trypsin mit derselben Quantität von Staphyl. aur., wie in Versuch 92, eingespritzt. Tod am 23. October. Section: Hyperämie des Peritonäum und hier und da sehr kleine Fibrinflocken von der Grösse grauer Tuberkeln. Unbedeutende Menge serös-blutigen Exsudates im Peritonäum und in beiden Pleurasäcken. Organe ohne besondere Veränderungen. Unter dem Mikroskope besteht das Exsudat ausschliesslich aus desquamirten Epithelialzellen des Bauchfellüberzuges und aus den eingespritzten Mikroorganiswen in Reincultur. Weisse Blutkörperchen spärlich. Die Staphylokokken liegen grösstentheils frei, nicht im Innern der Zellen und nur zuweilen im Protoplasma derselben. (Diese Erscheinung wird auch in den anderen Versuchen beobachtet.) In Agarzüchtung erscheint Staphylococcus aureus in Reincultur. Auf Durchschnitten der Milzkapsel, des Centrum tendineum und des Peritonäum wurden Staphylokokken gefunden. Tod an Peritonitis mycotica. 
Versuch 91. Am 22. October Parallelversuch zu dem rorigen. Tod am 23. October. Das Unterhantgewebe im Unkreise des Hautschnittes verdaut. Hyperämie des Peritonäum; eine charakteristische schleimige Flüssigkeit bedeckt die Gedärme in sehr unbedeutender Quantität. Besondere Veränderungen in den Organen werden nicht bemerkt. Eine unbedeutende Quantität durchsichtigen Exsudates. Im Peritonäalexsudat zeigen sich mikroskopisch sebr viele Zellen des Peritonäalepithels und Fiter'körperchen, mit Staphylococcus aureus vermischt; der letztere entwickelt sich in Agaranssaat. Tod an Peritonitis mycotica.

Versuch 96. Am 24. October wurde $\frac{1}{4} \mathrm{~g}$ Trypsin mit derselben Quantität von Staphyl. aureus, wie in Versuch 92, eingespritzt. Reichliche kleine fibrinöse Flocken auf allen Gedärmen. Starke Hyperämie der Darmserosa und grosse Ansammlung trüben Exsudates im Peritonäurn. Milz deutlich vergrössert und mit Fibrinflocken bedeckt, ebenso die Leber. Unter dem Mikroskope in Exsudate Eiterkörperchen; Mikroben wurden nicht gefunden. Auf Agarzüchtung Staphyl. anreus. Tod an Peritonitis fibrino-purulenta incipiens.

Versuch 97. Am 24. October Parallelversuch zu dem vorigen. Tod am 25. October. Hyperämie dej Serosa, charakteristische schleimige Fiüssigkeit im Peritonäum. Milz vergrössert. Die übrigen Organe obne besondere Veränderungen. Keine Fibrinflocken und kein Exsudat. Unter dem Mikroskope wenige Eiterkörperchen und Staphyl. aureus; letzterer erscheint auf Agarcultur. Tod an Peritonitis mycotica.

So sind denn auch alle Versuchsthiere dieser zwei letzten Reihen von Experimenten mit Staphylococcus aureus, Ol. crotonis und Trypsin an Peritonitis acuta zu Grunde gegangen. Hier wurden auf's Neue dieselben Formen der Peritonitis in derselben Reihenfolge, wie in den früheren Versuchen, festgestellt. Auf's Neue wurde die charakteristische Erscheinung beobachtet, dass je rascher der Tod des Thieres eintritt, um so weniger Veränderungen . in den Organen und im Peritonäum bemerkt wurden. Zuweilen nur begegnete man hier und da kleinen Fibrinflocken und unbedeutender Ansammlung charakteristischen Exsudates, welches sich durch und durch als eine ungehenı Züchtung der eingespritzten Mikroben darstellte. Zuweilen, wie im Versuch 97, waren weder jenes Exsudat, noch Fibrinflocken vorhanden; nur zwischen den Gedärmen wurde eine unbedeutende Menge fadenziehender schleimiger klebriger Flüssigkeit bemerkt, welche mit der Platinöhse auf Deckgläschen äbertragen ganz aus Staphylokokken bestand. Kurz die rasch sterbenden Thiere gingen an Peritonitis mycotica zu Grunde. Je länger das Leben des Ver- 
suchsthieres dauerte, um so mehr trat der hämorrhagisch-fibrinöse Charakter der Peritonitis hervor und darauf der fibrinöseitrige (P. incipiens). Bei länger dauerndem Leben des Versuchsthieres, mehrere Tage bis zu 5 Tagen, riefen dieselben Dosen, wie im Experiment No. 94, mit Ol. crotonis jedoch eine typische Peritonitis purulenta hervor.

Da, ich wiederhole es, die in diesen zwei Versuchsreihen eingespritzten minimalen Mengen von Ol. crotonis, Trypsin und Staphyl. aur. einzeln und für sich den Versuchsthieren unschädlich sind, so ist augenscheinlich der Schluss richtig, dass chemische Stoffe (Reizerreger) die Infection und Peritoni$t$ is begünstigen, oder, anders ausgedrückt: unbedeutende Quantitäten von Staphylococcus aureus rufen rascher und leichter Peritonitis hervor an einem, durch chemische Substanzen gereizten Peritonäum, als an dem gesunden.

Wir sehen aus allen beschriebenen Versuchen, dass ausser Erscheinungen, welche speciell den chirurgischen Kliniker interessiren, wir auch Gelegenheit hatten, bei unseren Experimenten eine Reihe pathologisch-anatomischer Formen von acuter Peritonitis zu beobachten.

Die Peritonäalhöhle ist von pathologisch-anatomischer Seito aus wenig bearbeitet in der Literatur. So findet man bei Klebs, Ziegler, Birch-Hirschfeld und Cornil ${ }^{1}$ ) nur unvollständige Erklärungen, welche von andern Autoren wiederholt werden. Eiu ausführliches Capitel über die Peritonitis acuta befindet sich bei Prof. N. P. Iwanowski ${ }^{2}$ ). Er unterscheidet ganz richtig eine Reibe von Formen der acuten Peritonitis: seröse, serös-fibrinöse, eitrige, fibrinös-eitrige und hämorrhagische. Nach seiner Ansicht kann die eitrige Peritonitis primär sein und selten wird sie als idiopathische Krankheit beobachtet, - „iscedka nablüdaetcja kak idiopatitzceskoe sabolewanie", - dabei werden als Ursachen derselben Infection, Schizomyceten und unter ihnen die pyogenen - "schisomiceti u meschdu nimi piogénnie kokki“ - betrachtet (p. 221). Endlich erwähnt Prof. I wanowski die Anwesenheit

1) Siebe die bekannten Lehrbücher dieser Autoren.

2) N. P. Iwanowski, Lebrbuch der pathologischen Anatomie „Ytzcebnik patologitschesk of Anatomie“. St. Petersburg 1888, p. 218 (russisch). 


\section{8}

der Bacillen, welche Eiterung erregen, bei Entzündung des Peritonäums durch Eintritt fäcaler Massen.

Da es uns gelang, eine Reihe von Formen der acuten Peritonitis experimentell hervorzurufen, so erlauben wir uns, unsere Angaben zu systematisiren und alle von uns beobachteten Peritonitisformen unter folgende Gruppen unterzubringen:

1. Peritonitis durch Wirkung chemischer Agentien. Crotonöl, Trypsin und chemische Stoffwechselproducte des Staphyl. aureus riefen die hämorrhagische Form hervor. Die Intensität der Hämorrhagien und des blutigen Exsudates schwankte und war veränderlich, indem sie von der Dosis der eingespritzten Substanzen abhing. Uebrigens traten zwei charakteristische Erscheinungen hervor: 1) Abwesenheit eitriger Elemente im Peritonäum und im Exsudate, und 2) Abwesenheit der Mikroben. Wir erregten im Peritonäum den stärksten Reiz, welcher die ganze Höhle mit einem colossalen Extravasat oder einer enormen Menge hämorrhagischen Exsudates füllte, in der Hoffnung, einen leichteren Durchtritt für die Mikroben aus dem Darme zu schaffen und auf irgend eine Weise die Mikroben aus dem Darme in das entzündete, blutige Peritonäum (so zu sagen) zu locken. Aber, dessenungeachtet, blieb sowohl bei diesen ungeheuren, als auch bei weniger heftigen Reizen die Peritonäalhöhle sterilisirt und die Impfung auf Agar und Fleisch-Pepton-Gelatine resultatlos. Mit einem Worte, der Durchtritt von Mikroben durch die Darmwand und die secundäre Infection des Peritonäums durch Mikroben wurden, sogar bei den heftigsten Reizen des Bauchfelles, nicht beobachtet, wenn die Section ungesäumt oder 1-2 Stunden nach dem Tode gemacht wurde. Bei Sectionen nach einigen Stunden oder nach einem Tage erscheinen schon Mikroben im Peritonäum aus dem Darmkanale und zwar öfter, als andere Fäulnissmikroben. Diese Erscheinung, das Eindringen der Mikroben nach dem Tode in das Peritonäum aus dem Darme, wurde von uns nicht selten auch bei anderen Experimenten beobachtet. Da ich dieselbe früher bei der Beschreibung der Versuche nicht erwähnt habe, so richte ich hier auf diese Erscheinung besonders die Aufmerksamkeit, als auf eine in - pathologischer Hinsicht äusserst interessante. Indem wir das 
oben Gesagte resumiren, können wir uns kurz fassen: a) chemische Substanzen, in das Peritonäum eingespritzt, rufen die hämorrhagische Form der Peritonitis hervor; b) die Peritonäalhöhle bleibt dabei frei von Mikroben bei lebender Darmwand.

2. Peritonitis in Folge einer Infection durch die Bauchdecken. Die Reihe der hier beobachteten, in ihrem ätiologischen Wesen identischen Formen unterscheidet sich jedoch scharf durch ihren pathologisch-anatomischen Charakter und kann je nach der Intensität der Krankheit und dem raschen Eintritt des Todes in folgende Unterarten eingetheilt werden:

a) Peritonitis mycotica. Sie stellt die höchste Stufe der Infection dar, mit tödtlichem Ende, früher als reactive Veränderungen im Peritonäum auftreten. Das Peritonäum ist zuweilen zum Theil mit einer charakteristischen schleimigen Flüssigkeit bedeckt, - eine Züchtung von Bakterien im Exsudate, zum Theil etwas hyperämisch, zum Theil hier und da mit Fibrinflocken bestrent. Auf Einzelheiten dieser Form in der Praxis und am Krankenbette wurde schon oben hingewiesen.

b) Intensive Infectionen erscheinen auch in der Gestalt der hämorrhagischen Form. Ihre verschiedenen Gestalten und Variationen wurden schon früher im Einzelnen besprochen. Ausser Extravasaten und Ecchymosen verschiedenen Grades und verschiedener Grösse, befindet sich im Peritonäum ein hämorrhagisches Exsudat in verschiedener Quantität, mit einer grösseren oder kleineren Beimischung eiteriger Elemente und einer Masse von Mikroben.

c) Es scheint, dass die fibrinös-eiterige Form möglicherweise durch eine weniger intensive Infection bedingt wird. Jedenfalls ist sie der Anfang der eiterigen Peritonitis, denn ausser durch Fibrin charakterisirt sie sich mehr oder weniger durch die Anwesenheit eines trüben, sogenannten katarrhalischen Exsudates oder auch zerstreuter, kleiner, eiterig-fibrinöser Heerde. Das erstere - das katärrhalische Exsudat - besteht unter dem Mikroskope hauptsächlich aus Eiterkörperchen und sollte die beginnende eitrige Peritonitis genannt werden. In dem zweiten, den eiterig-fibrinösen Heerden, ist das Fibrin entweder mit dem Eiter vermischt, oder die Eiterkörperchen sind im Centrum ein- 
geschlossen oder sie befinden sich in der Peripherie der Fibrinpartikelchen.

d) Bei unbedeutender Infection und länger dauerndem Leben des Thieres und bei für Mikroben günstigen, mechanischen und chemischen Bedingungen tritt die purulente Form der Peritonitis auf, welche sich entweder durch zerstreute dichte Eiterflocken, oder durch reichliches, flüssiges, eiteriges Exsudat im Peritonäalraume auszeichnet.

Endlich 3. Peritonitis in Folge von Infection von innen aus dem Darme - Peritonitis perforativa - kommt ebenfalls in verschiedenen Formen vor: die mykotische, die hämorrhagischeiterige, die fibrinös-eiterige, und endlich die eiterige - was von der Quantität und Qualität des Infectionsvirus abhängt. Die Ursache der acuten Perforativperitonitis in unseren Versuchen sind die Mikroben des Darmsaftes, für die Kaninchen der von uns beschriebene "Bacillus peritonitidis ex intestinis cuniculi". Die Bestimmung derjenigen Mikrobenarten, welche bei dem Menschen die Perforativperitonitis erregen, ist eine Aufgabe der nächsten Zukunft.

Was die Abscheidung des Fibrins durch das Peritonäum anbelangt, so scheint es uns, dass es eines der ersten Mittel ist, mit welchem sich dieses Organ vor den Feinden schützt, indem es dieselben durch eine fibrinöse Kapsel einhüllt. Wir fanden, dass dichte Klümpchen sterilisirten Darmsaftes und Agar-Agars ebensowohl, als Partikelchen mit Bacillen inficirten Darmsaftes und mit Staphylokokken inficirten Agar-Agars, in Fibrin eingehüllt wurden. Fibrin wurde auch abgeschieden und umgab ununterbrochen die Gedärme, die Leber und Milz in den Experimenten mit Culturen. Leider ist die Fibrinabscheidung bei der Infectionsperitonitis ein sehr ungenügendes Schutzmittel, indem die in das Peritonäum eingedrungenen Mikroben in den Fibrinflocken todtes Nährsubstrat finden, sich in ihnen reichlich vermehren, durchwachsen, (peptonisirend) die Schutzkapsel verflüssigen und aus ihr dann in grossen Massen in den Peritonäalraum gerathen.

Es bleiben zwei Erscheinungen zu erwähnen, welche zum Wesen der acuten Peritonitis gehören, die Vergrösserung der Milz bei Infectionen und das Exsudat in der Pleura. Beide 
Erscheinungen lassen sich rom Standpunkte der histologischen Structur des Peritonäalraumes und seiner physiologischen Function erklären. Nach den Untersuchungen von Recklinghau sen ${ }^{1}$ ), C. Ludwig und Anderen ist das Peritonäum ein ungeheurer Lymphraum, in allen seinen Wänden mit freien Oeffnungen - Stomata - versehen, welche mit den Lymphgefässen in Verbindung stehen, oder besser gesagt, den Anfang der Lymphcapillaren bilden. Diese lymphatische Peritonäalhöhle ist mit einer starken Pumpe ausgerüstet, - dem Diaphragma, - welche fortwährend die in das Peritonäum gerathene Flüssigkeit aufsaugt. "Flüssigkeiten", schreibt Landois"), "die in die serösen Höhlen gebracht, kommen daher mit Leichtigkeit in die Bahn der Lymphgefässe. Es haben sich so die Höhle des Peritonäums u. s. w." Ferner vergessen wir nicht, dass einerseits die Peritonäalwand so eng mit der Milzkapsel verwachsen ist, dass sie weder unterschieden, noch getrennt werden kann von der letzteren, sogar nicht unter dem Mikroskope, folglich stehen die peritonäalen Stomata in directer Verbindung mit den Lymphspalten der Kapsel der Milz und ihren Trabekeln. Auf der anderen Seite anastomosiren die Stomata und Lymphgefässe des Diaphragma mit den Lymphgefässen and Stomata, welche sich in der Wand des Pleuraraumes befinden. Wenn wir uns alle diese Einzelheiten vergegenwärtigen, so werden uns die beobachteten Erscheinungen verständlich sein, öftere Vergrösserung der Milz bei Infectionsperitonitis und Exsudat in der Pleura, zugleich mit Exsudat im Peritonäum.

Infections-Mikroben, indem sie in die Stomata gerathen, drängen sich durch sie in die Lymphspalten der Kapsel und Trabekeln der Milz, werden hier aufgehalten, theils vermehren sie sich, theils treten ihnen Armeen von Phagocyten des Blutes und der Milz entgegen. Es entsteht ein Kampf, in welchen

1) v. Recklinghausen, Zur Fettresorption, dieses Archiv Bd. 26 S. 172, bewies zuerst durch geistreiche Experimente das Vorhandensein der Stomata im Diaphragma, welche nach Einspritzung von Milch in das Peritonäum constatirt wurden: Milehkägelchen in den Stomata des Diaphragma.

2) Landois, Lehrbuch der Pbysiologie des Menschen. 3. Aufl. Wien und Leipzig 1883. S. 373. 
nach und nach das ganze Organ hineingezogen wird, was zum Ausdrucke kommt als Reizung des Milzgewebes - Proliferation der Milzphagocyten und Hyperplasie des Organs - Vergrösserung und Schwellung. Ausserdem werden die in das Blut gerathenen Mikroben von den Phagocyten in die Milz gebracht, was eine zweite Bedingung ihrer Schwellung darstellt.

In gleicher Weise werden die in das Peritonäum eingespritzten Flüssigkeiten und flüssigen Bestandtheile der entzündlichen Exsudate vom Diaphragma aufgesaugt, und indem sie in die weiten Stomata desselben eintreten, gehen sie hauptsächlich in den Ductus thoracicus, theilweise aber durch die Lymphcapillaren des Diaphragma, welche mit solchen der Pleura anastomosiren, und so fliessen sie durch die Stomata der Pleura in den Pleuraraum.

Das Vorhandensein der Stomata und der Zwerchfellpumpe schafft aber für das Leben und die Vermehrung der Mikroben im Peritonäum besondere physiologische Bedingungen, welche in manchen Fällen, ausser der virulenten Kraft der Mikroben, in der Ausbreitung der Peritonitis eine grosse Rolle spielen.

Wenn das Peritonäum ein lymphatischer Raum ist mit der Diaphragma-Pumpe, so müssen die in ihn eingebrachten Gifte vor allen Dingen in Lymphstomata und durch sie in die Lymphgefässe; den Ductus thoracicus, und durch das Blut in die ausscheidenden Nieren und die, mit der Infection activ kämpfenden Organe (Milz, Knochenmark) eintreten. Dies ist der Kampfesweg und die Art des Selbstschutzes gegen die Infection des Peritonäum von Seiten des Organismus. Dieser Schutz ist ohne Zweifel zuweilen genügend.' Wenn die Infection in geringer Quantität stattfand, die Mikroben klein sind, können sie rasch aus dem Peritonäum fortgeführt und durch den Ductus thoracicus und das Blut in entferntere Organe gebracht werden, wo sie metastatische Erkrankungsheerde erregen oder spurlos aus dem Organismus ausgeschieden werden. Wenn aber das in das Peritonäum eingebrachte Gift von einer bemerkbaren Grösse ist, z. B. Bacillen, oder in bedeutender Menge vorhanden ist, oder eine starke Vermehrungsfähigkeit besitzt, so verstopft es, einmal in die Stomata eingedrungen, dieselben direct oder indirect (Fig. 5a). In dem letzteren Falle, indem sie in das Protoplasma 
der Endothelzellen gerathen, welche die Stomata umkleiden, vermehren sie sich rasch in demselben; die übrigen Spalten füllen sich mit reuen Haufen von Mikroben, und nach und nach zeigen sich alle oder die meisten Stomata mit Mikroben vollgepfropft: Von diesem Augenblicke an hört die Aufsaugung der Flüssigkeiten von Mikroben in dem Peritonäum ganz auf oder sinkt bedeutend. Grosse Massen von Mikroben stapeln sich in den von dem Diaphragma entfernteren oder tieferen Theilen des Peritonäum auf; die Exsudation der Flüssigkeiten im Peritonäum dauert aber fort. Auf diese Weise werden für die Mikroben und die rasche Infection des Peritonäum äusserst günstige Bedingungen geschaffen: ruhige Vermehrung in einer ungeheuren Menge flüssigen, an Nährstoffen reichen, erwärmten Exsudates, und folglich rasche allgemeine Infectionsperitonitis früher, als die Erkrankung innerer Organe.

Der Kampf mit solchen Peritonitiden, mögen sie perforative oder durch Infection von aussen entstandene sein, ist nur auf chirurgischem $W^{\gamma}$ ege möglich, - durch frühe Laparotomie. Dieses ist der rein rationelle und einzig denkbare Weg für den Kampf in solchen Fällen. Nicht umsonst bewahrheitete sich die Laparotomie durch glänzende Resultate in einzelnen, durch englische und deutsche Chirurgen (Lawson, Tait, Spences Wells, Lücke u. A.) veröffentlichten Fällen. Die Laparotomie muss bei der acuten Peritonitis eine obligatorische Operation für den Arzt sein; je früher die Diagnose gemacht und die Operation ausgeführt wird, um so grösser wird die Möglichkeit sein, den Kranken zu retten. Deshalb ist die in der Literatur schon verbreitete Ansicht ganz richtig, dass der Chirurg sich wo möglich oft in solchen Fällen mit Therapeuten berathen soll.

Wir haben somit eine kleine Falte des Vorhanges über der Aetiologie und den Entstehungsweisen der Peritonitis acuta aufgehoben, und auf eine Reihe verschiedener ibrer Formen hingewiesen, welche durch chemische Substanzen und Mikroben bei Infection des Peritonäum von aussen oder von innen hervorgerufen werden. Die nächsten nnd Hauptaufgaben sind die Auffindung specifischer Mikroben der Perforationsperitonitis des Menschen and die Therapie der acuten Infectionsperitonitis in den Terminen und Perioden der Infection. - 
Ich fühle mich hier gedrungen, Herrn Dr. Friedrich Julius Rosenbach, Professor der Chirurgie in Göttingen, für seine liebenswürdige Ellaubniss, in seinem Privatlaboratorium zu arbeiten, und für seine, nir während der Arbeit gespendete, gütige Rathschläge meinen aufrichtigsten, herzlichen Dank darzubringen.

Diese Arbeit ist von meinem hochgeehrten Collegen, Herrn Geheimrath Dr. G., übersetzt. Meinen besten Dank dem Collegen, welcher trotz einer so schweren und undankbaren Arbeit mir nicht erlaubte, seinen Namen drucken zu lassen.

$$
\text { Tabelleder Ex perimente. }
$$

\begin{tabular}{l|l|l}
\hline Reihen. & Ausgang. & Diagnosis. \\
\hline
\end{tabular}

A. Chemische Substanzen.

\section{1. $\mathrm{R}$ e i h e. \\ oleum crotonis.}

26. Juli 1887. Eingespritzt einem Kaninchen 6 Tropfen in Eunulsion mit G. arabicum.

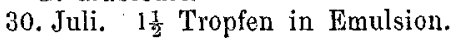

28. Juli. 2 Tropfen in Emulsion. Section gleich nach dem Tode. Auf Platten keine Mikroben.

28. Juli. 3 Tropfen in Emulsion. Auf Platten keine Mikroben.

3. August. 1 Tropfen in Emulsion.

3. Aug. 1 Tropfen in Emulsion.

15. Aug. 2 Tropfen (Hund) in Emulsion.

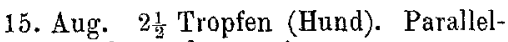
versuch zu dem vorigen.

16. Aug. $\frac{1}{4}$ Tropfen in Emulsion.

17. Ang. $\frac{1}{4}$ Tropfen (kleiner Hund) in Emulsion.
Tod am 27. Juli.

Tod am

30. Juli.

Tod am

29. Juli.

Tod am

29. Juli.

Tod am

3. Aug.

Tod am

6. Aug.

Tod am

16. Aug.

Tod am

16. Aug.

blieb am

Leben.

ebenfalls.
Peritonitis haemorrhagica.

ebenso.

ebenso.

ebenso.

ebenso.

ehenso.

Peritonitis haemorrhagica gravis. ebenso.

Bemerkung. Die meisten Versuche sind an Kaninchen angestellt. Es müssen daher alle, welche ohne Bezeichnung der Thiere mitgetheilt werden, Kaninchen zugescbribeben werden. Hunde aber und Meerschweinchen werden bei jedem Versuche gezeigt. Alle chemischen Stoffe und die Mikroben wurden in $7-8 \mathrm{ccm}$ Wasser (der Weite der Spritze) eingespritzt. Grösseren Quantitäten von Flüssigkeit sind in jedem Versuche besonders angezeigt. 


\begin{tabular}{l} 
Reiben. \\
\hline 26. Sept. $\frac{1}{\text { To }}$ Tropfen in Emulsion einem \\
Kaniuchen. \\
26. Sept. $\frac{1}{10}$ Tropfen. Parallelversuch \\
zu dem vorigen.
\end{tabular}

\section{2. $R$ e i h e. Trypsin.}

3. Oct. 0,5 Trypsin in 2 Spritzen Wasser.

3. Oct. 0,5 Trypsin in $1 \frac{1}{2}$ Spritzen Wasser.

3. Oct. 0,25 Trypsin in $7-8 \mathrm{ccm} \mathrm{HO}$ filtrirt und das Filtrat eingespritzt.

6. Oct. 0,1 Trypsin in $1 \frac{1}{2}$ Spritzen Wasser.

8. Oct. 0,05 in 1 Spritze Wasser.

\section{3. $\mathrm{R}$ e i h e.}

Kaltes Filtrat einer Cultur von Staphylococeus aureus.

17. Nov. $30 \mathrm{ccm}$ kalten Filtrates einer 8tägigen Cultur.

21. Nov. 2 Meerschweinchen je $20 \mathrm{ccm}$ und 2 je $15 \mathrm{ccm}$ kalten Filtrates einer 4tägigen Cultur.

$$
\text { 4. } R \text { e i h e. }
$$

Filtrat von Erysipelas-Streptokokken.

6. Nov. 2 Meerschweinchen wurden $15 \mathrm{cem}$ einer 4tägigen, in Dampf sterilisirten Erysipelascultur eingespritzt.

8. November wurden einem Meerschweinchen $15 \mathrm{ccm}$, einem anderen $20 \mathrm{ccm}$ eines kalten Infiltrates einer 5tägigen Erysipelascultur eingespritzt.

\begin{tabular}{|c|c|}
\hline Ausgang. & Diagnose. \\
\hline $\begin{array}{l}\text { ebenfalls. } \\
\text { ebenfalls. }\end{array}$ & - \\
\hline $\begin{array}{l}\text { Tod nach } \\
4 \text { Stunden. } \\
\text { Tod nach } \\
4 \frac{1}{2} \text { Stunden. } \\
\text { Todam } 5 . \text { Oct. }\end{array}$ & $\begin{array}{l}\text { Perit. haemorrhagica. } \\
\text { ebenfalls. } \\
\text { ebenfalls. }\end{array}$ \\
\hline Tod am $7.0 \mathrm{ct}$. & ebenfalls. \\
\hline lebt. & - \\
\hline $\begin{array}{l}\text { Tod am } \\
\text { 18. Nov. }\end{array}$ & $\begin{array}{l}\text { Perit. haem. exsudat. } \\
\text { Keine weisse Blut- } \\
\text { körperchen u. keine } \\
\text { Mikrokokken. } \\
\text { Dasselbe wie im vor- } \\
\text { hergehenden Falle. }\end{array}$ \\
\hline $\begin{array}{l}\text { blieben ge- } \\
\text { sund und } \\
\text { munter. } \\
\text { ebenso. }\end{array}$ & - \\
\hline
\end{tabular}

\section{B. Mikroben (Infection von aussen).}

5. $\mathrm{R}$ e i h e.
Nichtpathogene Mikroben, allein und mit 01 . crot.

3. Aug. Eine Spritze Agarcultur; mit Staphylococcus albus gleichaussehende Mikrokokken.

3. Aug. Ein dem vorigen paralleler Verssuch. blieb am

Leben.

ebenso. 
Reiben.

17. Aug. Einem Hunde wurden dieselben Mikrokokken aus 2 Agarculturen in einer Spritze eingespritzt.

18. Aug. Einem Kaninchen wurde 1 Spritze mit denselben Mikrokokken + $\frac{1}{30}$ Tropfen Ol. crotonis eingespritzt.

18. Aug. Parallelversuch. 17 Spritze Wasser. 0l. crotonis etwas mebr, als $\frac{1}{30}$ Tropfen.

26. Sept. $\frac{1}{10}$ Tropfen Ol. crotonis + Agarcultur der gelben Sarcina.

26. Sept. Parallel dem vorigen Versuch.

$$
\begin{aligned}
& \text { 6. } \mathrm{R} \text { e } \mathrm{i} \text { h e }{ }^{\mathrm{l}} \text { ). } \\
& \text { Staph. aureus. }
\end{aligned}
$$

13. Aug. Ganze Agarcultur in 2 Spritzen Wasser.

24. Aug. $\frac{1}{10}$ Tropfen 0l. crotonis und 5 Min. später Agarcultur von St. aureus.

27. Aug. $\frac{1}{10}$ Tropfen 01. crotonis mit. 2 Platinöhsen St. aurei.

29. Sept. Parallel dem vorigeu.

29. Sept. Parallel dem vorigen.

6. Oct. Eine Agarcultur in 1 Spritze Wasser.

6. Oct. Parallel dem vorigen.

11. Oct. 2 Platinöhsen von einer Agarcultur.

11. Oct. Parallelversuch.

13. Oct. Parallelversuch.

13. Oct. Parallelversuch.

13. Oct. Hund. Eine Agarcultur.

13. Oct. Hund. Parallelversuch zu dem rorigen.

17. Oct. (Vers. 78.) $\frac{1}{5}$ Platinöhse dés St. aurei.

17. Oct. (Vers. 79.) Parallel dem vorigen:

18. Oct. Eine Platinöhse mit Staph. filtrirt. Das Filtrat eingespritzt.

19. Oct. Filtrat ans $\frac{1}{5}$ Platinöhse (Vers. 86).

19. Oct. (Vers. 87.) 2 Platinöhsen: $5 \mathrm{ccm}$ Wasser, filtrirt; aus der Filtrate 2

Platinöhsen in einer Spritze Wasser.

20. Oct. (Vers. 88.) Die Hälfte der vorigen Quantität.

20. Oct. (Vers. 89.) Parallel dem vorigen.
Ausgang.

Diagnose.

ebenso.

ebenso.

ebenso.

ebenso.

ebenso.

Aug. Tod.

28. Aug. Tod.

30. Sept. Tod.

5. Oct. Tod.

14. Oct. Tod.

8. Oet. Tad.

12. Oct. Tod.

12. Oet. Tod

14. Oct. Tod.

14. Oct. Tod.

33. Oet. Tod.

14. Oct. Tod.

18. Oct. Tod.

18. Oct. Tod.

19. Oet. Tod:

20. 0ct. Tod. Periton. mycotica.

1. Nov. 'lod. Periton. purulenta.

blieb am

Leben.

ebenso.

Periton. fibrinosa. fibrinosa.

ebenso.

ebenso.

Per. purul.

bolische Pyämie.

mie.

Perit. purul. jncip.

Perit. myeot.

ebenso.

ebenso. rul. incipiens.

(incip.).

ebenso.

ebenso.
Periton. haemorrb.-

Per. purul. und em-

Perit, mycot. Pyä-

Perit. haemorrh. pu-

Perit. fibrin. haemor.

Perit. fibrin. purul.

i) Eine Reihe von Versucben dieser Serie, ganz analog den 1., 6. und 7 . sind in dieser Tabelle nicht angeführt. 


\begin{tabular}{|c|c|c|}
\hline Reihen. & Ausgang. & Diagnose. \\
\hline $\begin{array}{l}\text { 7. R e i h e. } \\
\text { Bacillus pyocyaneus (grüner Eiter). } \\
\text { 6. Oct. Fine Agarcultur in voller Spritze } \\
\text { Wasser. } \\
\text { 6. Oct. Parallelversuch. } \\
\text { 8. Oct. (Vers. 61.) } 1 \text { Spritze Wasser } \\
\text { mit 2 Platinohsen voll Mikroben. } \\
\text { 8. Oct. Parallel dem vorigen. } \\
\text { 10. Oct. (Vers. 67.) } \frac{1}{5} \text { Platinöhse. } \\
\text { 10. Oct. (Vers. 68.) Parallel dem vorigen. }\end{array}$ & $\begin{array}{l}\text { 7. Oct. Tod. } \\
\text { 7. Oct. Tod. } \\
\text { 9. Oct. Tod. } \\
\text { 11. Oct. Tod. } \\
\text { blieb am } \\
\text { Leben. } \\
\text { ebenso. }\end{array}$ & $\begin{array}{l}\text { Peritonitis fibrinoso- } \\
\text { haemorrh. mycot. } \\
\text { Perit. fibrin. haemor. } \\
\text { Perit. fibrin. haemor. } \\
\text { Perit. fibrin. purul. } \\
\text { incip. }\end{array}$ \\
\hline
\end{tabular}

\section{Darmsaft (Infection von innen).}

8. $\mathrm{R}$ e i h e.

Frischer Darmsaft, unfiltrirt.

27. Sept. (Vers. 36.) 1 Spritze Darmsaft.

27. Sept. (Vers. 37.) Parallel dem vorigen.

30. Sept. (Vers. 42). 1 Spritze Saft.

30. Sept. (Vers. 43). Parallel dem vorigen.

9. $R$ e i h è.

Frischer Darmsaft.

a) Filtrirter Darmsaft.

27. Sept. (Vers. 37a). 1 Spritze des durch einige Schichten Gaze filtrirten Darmsaftes.

27. Sept. $3 \frac{1}{2}$ Spritzen durch Papier filtrirten Darnsaftes.

30. Sept. Parallel dem vorigen. $2 \frac{3}{4}$ Spritzen eingeführt.

b) Darmsaft nach Tyndall sterilisirt.

5. Oct. (Vers. 50.) 1 Spritze im Laufe von 6 Tagen sterilisirten Darmsaftes. Die Sterilisation ist nicht vollständig gewesen, weil in den Impfungen die Streptokokken entwickelt sind.

5. Oct. (Vers. 51.) Parallel dem vorigen Versuch. $1 \frac{1}{2}$ Spritzen eingeführt.

8. Oct. (Vers. 59.) 1 Spritze des vollständig sterilisirten ( 8 Tage) Darmsaftes.

\section{0. $\mathrm{R}$ e i h e.}

Bacillus peritonitidis ex intestinis cuniculi.

6. Oct. (Vers. 57.) 4tägige Agarcultur in einer Spritze Wasser.
28. Sept. Tod. Perit. fibrinoso-haemorrh.

28. Sept. Tod.

1. Oct. Tod. Perit. fibrinosa.

2. Oct. Tod. Perit. fibrinoso-purulenta.

munter. Blieb am Leben.

ebenso.

lebt.

6. Oct. Tod.

Peritonitis haemorrb. Streptokokken im Exsudate.

14. Oct. Tod.

Peritònitis purulenta.

lebt und munter.

7. Oct. Tod. Perit. haemorrh. mycotica. 


\begin{tabular}{|c|c|c|}
\hline Reihen. & Ausgang. & Diagnose. \\
\hline $\begin{array}{l}\text { 6. Oct. (Vers. 58.) Agarcultur in einer } \\
\text { Spritze Wasser. }\end{array}$ & 7. Oct. Tod. & Perit.fibrino-haemor. \\
\hline $\begin{array}{l}\text { 8. Oct. (Vers. 63). 1 Spritze Wasser } \\
\text { mit } 2 \text { Platinöhsen mit Mikroben. }\end{array}$ & 11. Oct. Tod. & $\begin{array}{l}\text { Perit. fibrino - puru- } \\
\text { lenta (incipiens). }\end{array}$ \\
\hline $\begin{array}{l}\text { 8. Oct. (Vers. } 64 . \text { ) } 1 \text { Spritze mit } 2 \text { Pla- } \\
\text { tinöhsen mit Mikroben. }\end{array}$ & 9. Oct. Tod. & Perit. mycotica. \\
\hline $\begin{array}{l}\text { 17. Oct. (Vers. 80.) 2 Platinöbsen mit } \\
\text { Mikroben in } 1 \text { Spritze Wasser. }\end{array}$ & 18. Oct. Tod. & $\begin{array}{l}\text { Perit. fibrino-puru- } \\
\text { lenta (incip.) }\end{array}$ \\
\hline $\begin{array}{l}\text { 17. Oct. (Vers. 81.) Parallel dem Ver- } \\
\text { such } 80 \text {. }\end{array}$ & 19. Oet. Tod. & $\begin{array}{l}\text { Perit. acutissima pum } \\
\text { rulenta. }\end{array}$ \\
\hline $\begin{array}{l}\text { 17. Oct. (Vers. 82.) Parallel dem Ver- } \\
\text { such } 80 \text {. }\end{array}$ & 2. Nov. Tod. & Perit. purul. \\
\hline $\begin{array}{l}\text { 10. Oct. (Vers. 65.) Eine Spritze Wasser } \\
\text { mit } \frac{1}{5} \text { Platinöhse mit Mikroben. Locale } \\
\text { Darmgangrän und ein kleines Loch in } \\
\text { intestino. }\end{array}$ & 14. Nov. Tod. & Perit.? \\
\hline $\begin{array}{l}\text { 10. Oct. (Vers. 66.) Parallel dem vorigen } \\
\text { Versuch. }\end{array}$ & lebt. & - \\
\hline $\begin{array}{l}\text { 17. Oct. (Vers. 83.) Ein grosser Hund. } \\
\text { Eingespritzt Agarcultur von Mikroben. }\end{array}$ & 18. Oct. Tod, & $\begin{array}{l}\text { Perit. haemorrbagica } \\
\text { (mit Beimischung } \\
\text { von Eiterkörperchen } \\
\text { in dem Exsudate. }\end{array}$ \\
\hline $\begin{array}{l}\text { 17. Oet. (Vers. 84.) Kleiner Hund. Par- } \\
\text { allel dem Vers. } 83 \text {. }\end{array}$ & $\begin{array}{l}\text { 18. Oct. Hund } \\
\text { traurig. } 19.0 \mathrm{ct} \text {. } \\
\text { isst gar nicht, } \\
\text { steht mit halb- } \\
\text { gebogenem } \\
\text { Rücken. } \\
\text { 20. Oct. besser } \\
\text { und munterer. }\end{array}$ & Blieb am Leben. \\
\hline
\end{tabular}

D. Die Bedingungen der Mikroben bezw. die Infection begünstigende.

11. R e i.h e.

Agar-Agar + Staphyl. aureus.

A. 11. Oct. (Vers. 73.) $10 \mathrm{ccm}$ Fl.-P.Ag.-Ag., allein.

B. 24. Aug. (Vers. 23.) Staph. aur. ${ }^{1}$ ), ganze Agarcult. $+7 \mathrm{ccm}$ Fl.-P.-Ag.-Ag.

27. Aug. (Vers. 28.) $7 \mathrm{ccm}$ Fl.-P.-Ag.-Ag. +2 Platinöbsen mit Staph. aureus.

26. Oct. (Vers. 98.) I Platinöhse mit Stapbyl. aureus ist in $6 \mathrm{cem}$ Wasser aufgeschwemmt and filtrirt; aus dem Filtrate sind zu $7 \mathrm{ccm}$ Fl.-P.-Ag.-Ag. 2 Platinöhsen mit Staphylococcus zagefügt und mit Ag.-Ag. eingespritzt.

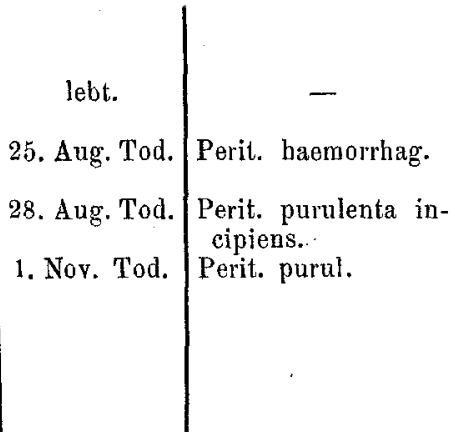

1) Die Reihe der ähnlichen Versuche 23 und 28 (mit grossen Mengen von Staphylokokken), welche später überflüssig erschienen, ist hier nicht angefïht. 
\begin{tabular}{l}
\hline Reihen. \\
\hline 26. Oct. (Vers. 99.) Parallel dem vorigen \\
Versuch. \\
26. Oct. (Vers. 100.) Parallel dem vorigen \\
(99.) Versuch. \\
26. Oct. (Vers. 101.) Parallel dem 100.
\end{tabular} Versuch.

$$
\text { 12. } R \text { e i h e. }
$$

Ol. crotonis + Staph. aureus.

22. Oct. (Vers. 92.) 1 Platinöbse voll Mikroben ist in $5 \mathrm{ccm}$ Wasser aufgesebwemmt und filtrirt; aus dem Filtrate sind 2 Platinöhsen genommen und in Mischung mit $\frac{1}{10}$ Tropfen 0l. crotonis eingespritzt.

22. Oet. (Vers. 93.) Parallel dem vorigen Versuch.

24. Oct. (Vers. 94.) $\frac{1}{20}$ Tropfen Ol. crotonis mit derselben Quantität von $\mathrm{Mi}$ kroben, wie in Versuch 92.

24. Oct. (Vers. 95.) Parallel dem vorigen Versuch.

13. R e j h e.

$$
\text { Trypsin + Staphyl. aureus. }
$$

11. Oct. (Vers. 71.) $\frac{1}{20} \mathrm{~g}$ Trypsin + 2 Platinöhsen mit Staphyl, aureus.

11. Oct. (Vers. 72.) Parallel dem vorigen Versucb.

22. Oct. (Vers. 90.) 1 Platinöhse des Staphyl. aureus in $5 \mathrm{ccm}$ Wasser aufgeschwemmt und filtrirt; aus dem Filtrate sind 2 Platinöhsen voll Mikroben genommen und zusammen mit $2_{2}^{\frac{1}{0}} \mathrm{~g}$ Trypsin eingespritzt.

22. Oct. (Vers. 91.) Parallelversuch.

24. Oct. (Vers. 96.) $\frac{1}{40} \mathrm{~g}$ des Trypsins mit derselben Quantität von Mikroben, wie in Versuch 90.

24. Oct. (Vers. 97.) $\frac{1}{40} \mathrm{~g}$ Trypsin mit derselben Quantität von Mikroben, wie im vorigen Versuche.
Diagnose.

28. Oct. Tod. Perit.fibrino-haemor. exsudativa.

28. Oct. Tod. Perit. fibrinosa.

28. Oet. Tod. Perit. fibr. haemorrh.

23. Oet. Tod. Perit. fibrino-purulenta (incip.).

23. Oct. Tod.

ebenso.

29. Oct. Tod. Perit purul.

28. Oct. Tod. Perit. mycotica.

12. Oct. Tod. Perit. acutissima fibrinosa haemorrb. 12. Oct. Tod. Perit.fibrino-haemor. 23. Oct. Tod. Perit. mycotica.

23. Oct. Tod. Perit. mycotica.

25. Oct. Tod. Perit. fibrino-purulenta (incip.)

25. Oct. Tod. Perit. mycotica.

\section{Erklärung der Abbildungen. Tafel XIV.}

Fig. 1. Staphylococcus aureus in den lymphatischen Spalten des Peritonaeum parietale (Kaniuchen, Versuch 85). a Peritonäumsepithel; b b b Staphylokokken zwischen Epithelzellen und in den lymphatischen Spalten; c Muskelfaser. 
Fig. 2. Staphyl. aureus in den lymphatischen Spalten des Centrum tendineum des Diaphragma. a a Staphylokokken; b b Bindegewebszellen (Kaninchen Versuch 85).

Fig. 3. Bacillus pyocyaneus in den Nieren des Kaninchens. a Gut gefärbte Bacillen in den Harnkanäleben; b etwas entfärbte Bacillen; c Bacillen in den Jymphatischen Spalten und in der Leukocyte; d Querschnitt des Harnkanälchens mit Masse der Bacillen.

Fig. 4. Bacillus peritonitidis ex intestinis cuniculi. a Isolirte Bacillen aus Agarreincultur; $a_{1}$ etwas zerfallene, anf Bacillen gefärbte Fäden aus Cultur jm hängenden Tropfen; b rngefärbter Faden aus Cultur im bängenden Tropfen.

Fig. 5. Bacillus peritonitidis im Centrum tendinenm des Kaninchens (Versuch 63). a Endothelzelle bei Stomatitis; b das letzte ist mit Bacillen vollgestopft; $c$ dieselben Bacillen in den lymphatischen Spalten des Zwerchfells.

Fig. 6. Dieselben Bacillen in den Nieren des Hundes (Versucb 83). a Bacillen in einer Lymphspalte zwischen Harnkanälchen; b in Harnkanälchen.

Hartuack $\frac{1}{12}$ Oeliwmersion, Ocular 3. 